\title{
TIO/SNA-- 146
}

CONTRACT SNP-1

SUPPLEMENT A70-C TO APPENDIX B STATEMENT OF WORK

Covering 1 October 1969 through 30 September 1970

NERVA Program

7 July 1970 Revision

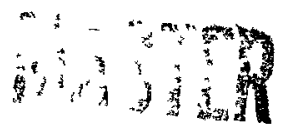

A DIVISION OF AEROJET-GENERAL 


\section{DISCLAIMER}

This report was prepared as an account of work sponsored by an agency of the United States Government. Neither the United States Government nor any agency Thereof, nor any of their employees, makes any warranty, express or implied, or assumes any legal liability or responsibility for the accuracy, completeness, or usefulness of any information, apparatus, product, or process disclosed, or represents that its use would not infringe privately owned rights. Reference herein to any specific commercial product, process, or service by trade name, trademark, manufacturer, or otherwise does not necessarily constitute or imply its endorsement, recommendation, or favoring by the United States Government or any agency thereof. The views and opinions of authors expressed herein do not necessarily state or reflect those of the United States Government or any agency thereof. 


\section{DISCLAIMER}

Portions of this document may be illegible in electronic image products. Images are produced from the best available original document. 
Pursuant to Article I, Section 2, Contract SNP-I, Supplement A7OB to Appendix B as modified by this Supplement ATOC to Appendix B delineates the portions and features of the work provided for in Section I of said Article I which the contractor shall perform during the period october 1, 1969 through september 30, 1970. It is understood and agreed by the parties that the contractor, Aerojet Nuclear Systems Company (ANSC) a division of the Aerojet-General Corporation, is committed to perform all of the work under Contract SNP-I as defined in these Supplements and that payment to the contractor of the full fee amount negotiated will be predicated upon completion by ANSC of this contractual comitment.

Due to the nature of the contract work and the administrative and contractual procedures to be applied, the performance of the contractor's work, including the meeting of such major milestones as may be set forth in the contract, may be affected by the performance of the major subcontractor, Westinghouse Astronuclear Laboratory (WANL) a division of the Westinghouse Electric Corporation, as well as by actions which may be initiated by the Government. For this reason, it is the intent of the parties to set forth herein further amplification of certain mutual understandings to be utilized in making a final assessment of the CY 1970 work actually performed by the contractor.

\section{A. Acceptance of $\mathrm{DRB} / \mathrm{PDR}$ Data Items}

1. The engine design DRT3/PDR data items to be submitted shall conform in content and maturity to the description conveyed in NERVA Data Item Description, Release No. 4, dated May 15, 1970, as supplemented and modified by the work statements, and as may be further modified by mutual written cogreement. The content of these data items where applicable shall be in consonance with trade study conclusions that have been confirmed in writing and in consonance with the approved engine and NSS CEI specifications. Contracting officer acceptance of the data items as satisfying the requirements of the contract will be based on the foregoing.

2. Formal Government approval of the DRB specifications will be confined to the engine and NSS CEI Specifications. The Government will approve or provide comments as to what is required to receive approval on these specifications within thirty (30) days after their receipt. If the Government provides comment or direction beyond the thirty (30) day period, an equitable adjustment will be made in the affected areas of work.

All subsequent contract events are predicated on Government approval by March 1, 1970 of the concept selections resulting from the B and B-prime trade studies. To the extent this is not accomplished, or concept selections previously approved are subsequently reversed by the Government, an equitable adjustment will be made in the affected areas of work. 
The work program defined herein relative to the engine flow systems is predicated on the S-3 flow schematic selected by the Government on May 14, 1970.

\section{B. Interim Milestones}

The interim milestone dates set forth in $\mathrm{H}$ of this Preface are included in the contract work statement to mor e clearly define the contractor's plan to perform major engineering effort in accordance with an established schedule. While there are no specific portions of the contractor's fee associated with meeting each of the contractual milestone dates, it is mutually understood and agreed that, in the event contractually required work is not completed within the CY 1970 contract year, a bilateral determination shall be made of the value of incomplete CY 1970 work at the year's end, and the contractor's CY 1970 fee amount may be adjusted accordingly by supplemental agreement to the contract.

\section{WANL Interfaces with ANSC}

It is recognized that satisfactory performance by ANSC of a number of its contractual commitments during CY 1970, including the timely meeting of contractual and other milestones, depends to varying degrees on timely receipt of WANL input data of acceptable quality. In the event of the subcontractor's failure to make timely submission of required data to ANSC and the performance of ANSC contractual work is thereby delayed or degraded, ANSC will endeavor to minimize the impact of the experienced delay. Such action may of necessity include deferral of the completion of ANSC work until a subsequent contract period, in which case a bilateral determination shall be made of the value of incomplete CY 1970 work at the year's end, and the contractor's CY 1970 fee amount shall be adjusted accordingly by supplemental agreement to the contract. However, to the extent to which inefficiencies occur, rather than a deferral of effort, occasioned by the subcontractor's failure to make timely submittal of required data to ANSC, and ANSC fee adjustments will be based on the ANSC effort expended rather than the degree of accomplishment.

D. The contractor shall comply with the following documents in conducting the work under this contract:

1. SNPO-NPRD-1, NERVA Program Requirements Document, Release 7, dated January 19, 1970, consisting of 50 pages, and Appendix B thereto, consisting of 10 pages.

2. SNPO-C STIE, NERVA Engine Specification Tree, dated March 23, 1970, as modified by ECP-O111B dated June 1, 1970.

3. SirP-C-1, Structural Design Specification, dated December 19, 1968. 
D. Continued

1967.

4. SNPO-C-3, High Pressure Gas Vessel Specification, dated November

5. SNPO-C-4, Quality Assurance Requirements for Facility and GSE,

Revision 1, dated september 1969 as applicable to new facilities and modifications to existing facilities. May 15, 1970.

6. SNPO-C Document, NISRVA Data Item Description, Release No. 4, dated

7. Maturity of Data Items for Engine Design Preliminary Design Review, as stated in ANSC letter 7010:265 dated May 28, 1970, Subject: Revised CY 1970 Work Plan, as revised by ANSC letter 7012:3099 dated June 30, 1970, same subject.

8. NASA Publication, INPC 200-2, April 1962, as interpreted by ANSC, Product Assurance Program Plan (Data Item P-017), dated September 30, 1969, as approved by the Contracting Officer and as modified by ECP O23A.

9. NASA Publication, NHB 5300.4(3A), as interpreted by NRO Workmanship Standard, ANSC-STD-9012.

10. Als RC Reliability Program Plan, Data Item R-101, Preliminary Draft, dated December 1, 1969.

11. Data Item C-018, ANSC Configuration Management Plan, dated September 30, 1969, as accepted by the Contracting Officer and as modified by ECP 0024B.

12. Data Item C-100, ANSC Data and Document Management Plan, dated September 30, 1969, as accepted by the Contracting Officer.

E. Engine Design Preliminary Design Review

A significant portion of the scope of work delineated herein involves the conduct of an engineering effort documented in data items which shall be submitted to support an Engine Design Preliminary Design Review. The maturity of the data items to be submitted to support the Engine Design Preliminary Design Review shall, as a minimum, comply with the requirements stated in ANSC letter 7010:265 dated May 28, 1970, Subject: Revised CY 1970 Work Plan, as amended by ANSC letter 7012:3099 dated June 30, 1970, same subject, and the detailed maturity defined by individual project work statements.

\section{F. Data Items}

In the performance of the scope of work delineated herein, the contractor shall prepare and submit data items which document the engineering work. The content of the data items to be submitted shall comply with the intent of the SNPO-C Form 9 Data Item Description, and the data items shall include at least the specific requirements delineated in the individual project work statements associated with each data item. 
G. Detailed planning and schedular data (networks, bargraphs, milestone charts, etc.) for the CY 1970 work program shall be prepired and continuously maintained for each project and shall be available to the Government for review and information as required.

\section{H. Contractual Milestones}

In the performance of the scope of work defined herein, the following milestones shall be accomplished on or before the dates specified:

No.

Milestone Description

Date

1 Complete the $B$ and $B$-prime trade studies to that level permitting Government concurrence on the conceptual engine selection.

Feb. 1970

2 Submit the following Part I Specifications, Sections 1, 2, 3, 6 and Preliminary 10 to establish the Design Requirements Baseline and submit the traceability data which documents the basis of the content of the Specifications:

CP-90290 NERVA Engine.

EC-90117 Propellant Shutoff Valve \& Actuator

EC-90121 Turbine Block Valve and Actuator

EC-90122 Bypass Control Valve \& Actuator

EC-90149 Turbopump Assembly

EC-90151 Nozzle Assembly Subsystem

EC-90154

$\mathrm{EC}-90155$

EC-90177

EC-90179

$\mathrm{EC}-90192$

$\mathrm{EC}-90214$

$\mathrm{EC}-90218$

$\mathrm{EC}-90242$

$\mathrm{EC}-90243$

$\mathrm{EC}-90244$

$\mathrm{EC}-90246$

EC-90152

EC-90257

EC-90258

$\mathrm{EC}-90276$

EC-90261

EC-90280

EC-90281

$\mathrm{EC}-90282$

EC-90283
Pressure Vessel \& Closure System

Electrical Power, Instrumentation \& Control

Engine Instrumentation

Wiring Harness

Structural Support Coolant Valve

Instrumentation \& Control Subsystem

Propellant Feed Subsystem

Destruct Subsystem (Dec. 1969 issue)

External Shield Subsystem

Gimbal Assembly Subsystem

Pump Discharge Check Valve \& Actuator

Thrust Structure Subsystem

Bypass Block Valve \& Actuator

Cooldown Supply Control Valve \& Actuator

Cooldown Supply Coitrol Valve \& Actuator

Structural Support. Block Va'ive \& Actuator

Pump Discharge Valve and Actuator

Turbine Discharge Block Valve and Actuator

Pump Discharge Valve and Actuator

Turbine Throttle Valve and Actuator
June 1970

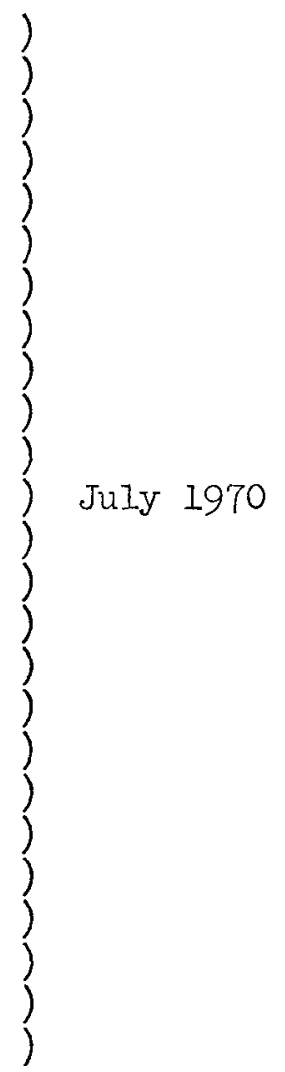

(c)

(c)

(c)

(D) 
DS-90124

DS-90125

DS-90135

DS-90176

DS-90196

DS-90251

DS-90253

DS-90262

DS-90263

DS-90264

DS-90265

DS-90266

DS-90267

DS-90269
Turbine Inlet Line

Turbine Discharge Line

Pump Discharge Line

Nozzle Extension

Nozzle

Gimbal Actuator

Propellant Inlet Iine

Cooldown Lines

Stage Tank Pressurization Line \& Check Valve

Engine Purge Unit

Structural Support Coolant Lines

Turbine Bypass Line

Upper Thrust Structure

Lower Thrust Structure

July 1970

(D)

3 Submit the data items to support the Engine Design

Preliminary Design Review in accordance with the

matrix provided as Enclosure 3 to ANSC letter 7010:265

dated May 25, 1970 (Item 13 in Paragraph $D$ above) and

to the detailed maturity defined by individual project

work statements.

Sept 1970

C-002 Part I, Preliminary Section 4 for the engine and 31 subsystems or components, consisting of a matrix

(c) indicating the method (e.g., analysis test, etc.) of verifying Section 3 requirements.

E-105 Engineering Data - Design Evaluation

E-106 Engineering Data - Interface Control

S-023 Natural Enviornment Analysis Report

S-031 Thermal \& Fluia Flow Analysis Report

S-036 Structural Analysis Report

S-038 Dynamic Analysis Report

S-039 Loads Analysis Report

S-047 Mass Properties Analys is Report

S-052 Functional Flow Diagrams

S-053 Requirement Allocation Sheets

S-055 Schematic Block Diagrams

S-056 Time Iine Sheets

S-110 Radiation Effects Analysis Report

S-114 Reference Mission Data Book

4. Complete analysis of data from XE-Prime test series and

issue Data Analysis Report

May 1970

5 Complete and issue test report for Phase IA twin TPA testing - Test Cell "C"

July 1970

6 Place purchase order for fabrication of turbine housing air flow/performance test hardware, pump air Ilow/performance test hardware, pump $\mathrm{LH}_{2}$ suction performance test hardware. 
$7 \quad$ Place purchase order for fabrication of rotor and stator blade, vibration test hardware

Sept 1970

8 Complete preparation of preliminary specification control drawings and preliminary specification for procurement of binary valve actuator motor test specimens

April 1970

9 Procure electric motors, and test fixtures to support the design feasibility testing of the binary valve actuators

Aug 1970

10 Conduct initial feasibility tests of electric motors for binary valve actuators and determine the dynamic motor characteristic

Sept 1970

11 Design low cycle nozzle thermal fatigue test specimens, prepare test plan and release fabrication drawings

May 1970

12 Place purchase order for the following tooling and hardware associated with the nozzle skirt extension:

July 1970

a. Wrap Mandrel, Honeycomb Layout Equipment, Curing and Carbonizing Equipment, Demo Skirt Extension Material.

13 Complete modification of existing AGC facilities for skirt extension carbonization process

Aug 1970

14 Complete preparation for GTR-22 test

Aug 1970

15 Issue the NERVA Program Test Plan (T-101)

JuIy 1970

I6 Submit an initial draft of that section of the NERVA Facilities Requirements Plan (F-003) associated with NERVA Engine, Reactor and Engine Component Development and Qualification, and Test Facility Requirements

Sept 1970

17 Submit the Steam Generator Procurement Specification (C-002)

April 1970

18 Submit the NASS Duct Preliminary Design Package (F-008)

Sept 1970

19 Submit an Engine/Facility Compatibility Safety Study of the NERVA Engine as specified in Project 241

Sept 1970

20 Issue the following reliability methods and procedures required to support the engine and component PDR's:

System \& Component Reliability Mathematical Models

July 1970

Statistical Distributions and their applications and tables

July 1970

Failure Rate Derivation

July 1970 
No.

21 Issue the reliability methods and procedures required to support the future development program as delineated in work statement for Project 263, paragraph 1.c.(3). 


\section{CONTRACT SNP-I \\ SUPPLEMENT A70-C TO APPENDIX E}

PROJECT WORK STATEMENTS 


\section{PROJECT 101 - MISSION STUDIES AND ANALYSIS}

Suffix $f$ - Development Engineering

1. Prepare and issue Data Item S-114 for Hot Bleed Engine Missions.

2. Complete Mission and Vehicle analysis in support of the NERVA Engine Program.

3. Complete mission and mission performance analysis in support of studies which determine the vehicle imposed engine requirements.

4. Complete analysis to update the S-114 NERVA Mission Data Book including missions as defined in Appendix B of IVFRD-l, Revision 7 .

5. Preparation of updated Data Item S-114 in support of PDR shall be in process. 
Suffix $f$ - Development Engineering

1. Provide engineering support necessary to assure that the NERVA Engine is integrated with the total system (stage, vehicle and support systems).

2. Continually evaluate the NERVA Engine requirements and coordinate with design.

3. Update, issue and maintain the "NERVA Reference Data Book" $(S-130)$ for use by program participants and to support engine PDR.
a. Preliminary Issue
b. Final Issue
c. Deleted

4. Verify the following NERVA Program Requirements Document items and issue Change Proposal or confirming letter, if applicable, to support Engine PDR:

\begin{tabular}{|c|c|c|c|c|}
\hline T.S. & Page & Section & NPRD Item & Value \\
\hline & 2 & $\operatorname{III-B-IA(I)}$ & Thrust Accuracy & $\begin{array}{l} \pm 20001 \mathrm{~b} . \\
\text { force }\end{array}$ \\
\hline 025 & 2 & $I I I-B-I A(3)$ & Nominal Chamber Pressure & 450 psia \\
\hline 025 & 3 & $I I I-B-I c$ & Chamber Pressure & 450 psia \\
\hline 026 & 3 & III-B-Ic & Throttled Chamber Pres. & (tbd) psia \\
\hline & 3 & III-B-Ic & $\begin{array}{l}\text { Rate-of-Change of Cham- } \\
\text { ber Pressure }\end{array}$ & $50 \mathrm{psi} / \mathrm{sec}$ \\
\hline 026 & 3 & III-B-Ic & $\begin{array}{l}\text { Duration at Throttled } \\
\text { Chamber Pressure }\end{array}$ & $(t b d) \min$. \\
\hline 026 & *3 & III-B-Ic & $\begin{array}{l}\text { Thrust with } 15 \% \text { Vapor at } \\
\text { Tank Outlet }\end{array}$ & (tbd) $1 b$ \\
\hline 026 & $* 3,4$ & $I I I-B-1 d$ & Paragraph 1 & Entire Para. \\
\hline 026 & $* 4$ & III-B-Id & Paragraph 2 & "at any time" \\
\hline œ26 & $* 4,5$ & $I I I-B-I d$ & Paragraph 3 & Entire Para. \\
\hline 026 & $* 5$ & $I I I-B-I d$ & Paragraph 4 & lst Sentence \\
\hline ०22 & *5 & III-B-Id & Para. 4; thrust nulling & After (tbd) sec. \\
\hline 021 & 5,6 & $\operatorname{III-B-Ie}(I)(3)$ & 3-Sigma Iimits & All values \\
\hline 025 & $* * 2$ & $\operatorname{III}-B-I a(5)$ & Engine Weight Max. & $(t b d) I b$. \\
\hline 023 & $* * 2$ & III-B-Ia $(6)$ & Shield Weight Max. & (tbd) $1 b$. \\
\hline & $* * 7$ & $I I I-B-I g$ & Leakage during Non-Opr. & $400 \mathrm{St} . \mathrm{Cu} . \mathrm{in} / \mathrm{min}$. \\
\hline & $* * 9$ & III-B-In & Storage & Entire Sec. \\
\hline
\end{tabular}


PROJECT 102 - Continued

\begin{tabular}{|c|c|c|c|}
\hline Page & Section & NPRD Item & Value \\
\hline$* * 18$ & III-B-8a(1)(6) & NERVA Engine Features & All Features \\
\hline$* * 24$ & III-B-9 & High Reliability Stds. & Specification \\
\hline$* * 3 I$ & III-C-3 & $\begin{array}{l}\text { Guideline Engine Test } \\
\text { Program }\end{array}$ & Entire Sec. \\
\hline
\end{tabular}

*These items may be verified by utilizing engineering judgment based on experience to date and available data in lieu of performing detailed system analysis.

**Completion not scheduled for CY 1970.

5. Prepare preliminary Engine Acceptance Criteria. 
PROJECT 1II - EIIGINE SYSTEMS ANALYSIS

Suffix b - Technology Engineering

1. Analyze data from the XE Prime test series which will be used as a basis for INERVA Fingine models. The Data Analysis Report shall be issued such that the scope and depth of data analysis are comparable to previous data analysis reports for major test items, e.g., AGC Report RIJ-S-0309, NRX/EST Data Analysis. In this report include transfer function data analysis from $\mathrm{XE}$ test series and identify difference between CAM and test data.

Suffix $f$ - Development Engineering

1. Prepare source data for updating the S-001 Data Item, Systems Analysis Summary Report to support engine PDR. The report provides results of the systems analysis for the NERVA Engine, its subsystems and components. The report will be documented by internal AGC memorandum.

2. Complete the required inputs to the Propellant Feed System Trade Study (TS-101). This wiIl be reported by internal memoranda and by presentation to SNPO.

3. Complete and publish the following trade studies:

a. TS-025 - Engine Chamber Pressure Trade Study

b. TS-022 - Post Shutdown Operation Trade Study

c. TS-026 - Startup, Shutdown Ramps and Throttling Trade Study.

4. Complete and publish Engine System Rated Performance Trade Study (TS-021). The trade study report shall include a preliminary evaluation of allowable tolerances on engine and component state points. These tolerances shall be determined by propagation of error analysis, using partial derivatives. At least two (2) of the sets of engine rated performance state points shall be calculated using the NBS generating deck for determination of turbine performance.

5. Provide engine state points and component tolerances for use in preparation of engine subsystem and components specifications, Section 3. This information will be documented by internal memoranda and as inputs for test specifications.

6. Perform transient analysis for use in the NERVA Engine specifications. This work will be documented by internal memoranda and input to S-001 Data Item. 
7. Deleted

8. Maintain, issue and update the Common Analog Model of the NERVA engine system. The model includes the nuclear subsystem, propellant feed system, and EIS-I facility emergency systems. The CAM will be coordinated with WANI and upgraded based on component design and test data. The model will be capable of analyzing transient system performance, malfunctions and in sufficient detail for control system design.

9. The Nuclear Engine Transient Analysis Program (NETAP) will be updated and modified as required to perform the engine systems analysis for the NERVA engine. Modifications will include inclusion of the dual turbopump; improvements in the turbine representation; updating to any component configuration changes; improvements in input/output format. These modifications will be documented by internal memoranda and in the annual summary report.

10. Maintain and modify the Simplified Engine Program (SEP) to the full-flow configuration. These modifications will include the ability to handle various valve configurations; improvements in the turbopump representation; improvements to better handle hydrogen properties. The work will be documented in internal memoranda and as part of the annual report. A copy of the program will be provided to SNPO.

11. The Flight Engine Program (FEP) will be maintained and upgraded for use in trade study applications. The modifications to it will include the ability to handle varying types of after-cooling profiles, tank heating, integration of decay products. This wor $k$ will be documented by internal memoranda and in the annual report.

12. Define cooldown requirements for EIS-1. This will be performed as Trade Study No. 1014. This will be documented in trade study report to be issued in CY 1971.

13. Engine system analysis in support of Category A, B and C trade studies will be provided. This work will be documented by internal memoranda, quarterly and annual reports. 
Rev. $7-7-70$

PROJECT 112 - ENTGINE SYSTEM DESIGN

Suffix f - Development Engineering

1. Prepare a reference flight engine layout drawing as the baseline configuration for Trade Studies and other design and analysis efforts.

2. To support Conceptual Engine PDR, conduct layout design studies and prepare drawings of alternate engine concepts toward systems optimization in terms of flight performance, maintainability, reliability, structural integrity and ground testing. Particular emphasis will be directed toward engine length/weight optimization. Select the engine PDR concept based on the trade study recommendations and the results of the engine conceptual design studies.

3. Prepare design layout drawings of the selected concept. Conduct design and analysis studies in support of the engine design and upgrade the layout drawings as these efforts mature.

4. Provide engine system design direction to the subsystem/component design efforts including the WANL/NSS. Establish a Project Engineering critique and review function of those efforts with the lead responsibilitJ for the NERVA engine design being with Project $112 f$.

5. Prepare piping and flow schematic drawings to support the prime engine layout design definition.

6. Prepare preliminary instrumentation cable routing drawings to support the prime engine layout design definition in accordance with the MRI requirements.

7. Maintain an engine design data book to document the design effort.

8. In support of Engine PDR, accomplish the following tasks:

a. Provide preliminary E-105 for review.

b. Provide preliminary S-03I data for review consisting of structural thermal profiles for steady state full power and pre-fire coast operations.

c. Provide preliminary S-036 data for review consisting of preliminary analyses of major engine components (i.e., thrust structure and pressure vessel, nozzle, TPA and skirt). The analyses will include calculation of the primary stresses and margins of safety due to the launch vehicle operation loads and the nuclear space 
operation full power steady state loads.

d. Provide preliminary S-038 data for review. The results of an engine preliminary modal analysis will be included. Dynamic Response environments will be determined at the major component interfaces for the launch vehicle operation and the nuclecrr space operation stegidy state point. Transient, malfunction and power points other than full power will not be analyzed. Flight safety influences will not be considered nor will handling and transportation environments.

e. Provide preliminary S-039 data for review, consisting of steady state launch vehicle operation and steady state nuclear space operation loads.

f. Provide preliminary S-047 data for review, providing weight, center of gravity data, and moment of inertia.

g. Initiate preparation of Data Item R-201. Eiffort will include prelirinary analysis covering expected frequency of maintenance actions, estimated component/module replacement times and comparisons with allocated time. Maintainability considerations developed as a part of this work will be fed directly into the engine design.

9. Establish and maintain a Project Engineering function to provide direction, coordination, review and approval of those analytical efforts associated with Data Items $S-100$ and $S-1 J 2$ for the engine design.

10. Provide engine system design support to AGC Change Board and other configuration control activities.

11. Deleted

12. Provide a system design review and input function to the engine/ subsystem/component specifications.

13. Initiate preparation of qualification ground test engine layouts, piping/flow schematics and instrumentation cable routing drarings. 
14. Participate on the Environmental Ioads Committee to provide the following:

a. Engine dynamic analyses

b. Engine to stage interface coordination to establish engine dynamic requirements such as engine frequencies.

15. Provide maintainability design requirements for engine and components and update as required to support DRB.

a. Provide interface criteria for engine-to-stage and engineto-reactor, pressure vessel, nozzle assembly.

b. Provide component or modular subsystem maintainability design criteria.

16. Conduct Trade Study 1003 to establish the remote interface planes, to determine which components should be packaged in the engine such that they can be maintained, and determine the extent that modular subsystems versus component packaging should be utilized. This study will be used to provide information for ergine conceptual definition. The results of T. S. 1003 shall be documented in Data Item $\mathrm{S}-054$.

17. Prepare Data Item R-102.
a. Prepare and submit Form 9.
b. Prepare and submit Data Item.

18. Plan and conduct a program to monitor, allocate and control the NERVA Flight Engine weight. Emphasis will be placed on weight reduction consistent with other engine performance requirements.

19. Continue design studies and prepare layout drawings of the engine concept. The objective of the studies will be to minimize the shield weight from that projected during the February trade study meetings.

20. Perform design studies of various engine/external shield configurations. The concepts shall permit the shielding to be removable or replaceable either on the ground or in space either before or after the engine has been operated. Such removal or replacement shall be achievable during non-operating periods between missions. Evaluate results and select concept for engine design. 
Suffix b-Technology Engineering

1. Provide engineering support necessary to complete technology program.

2. Prepare and issue the Final Test Report for the XE Test Program based upon the Spear Memoranda plus special areas of interest not covered by them and shall include both an analysis and explanation of significant engine related anomalies encountered during the XE Test Program.

\section{Suffix f - Development Engineering}

1. Provide engineering support necessary to perform NERVA Engine verification planning and management activities.

2. Support preparation of the NERVA Program Test PIan (T-101).

3. Prepare, issue and update the Section 4.0 of the NERVA Engine CEI Part I Specification (C-OO2) as a separate preliminary document.

4. Coordinate the Section 4.0 of the Subsystem and Component specifications and design sheets. (Review and approval functions are covered in Project 119). Coordinate and review subsystem and component Verification/Qualification planning.

5. Prepare a document summarizing all known engine level testing requirements as input to the NERVA Test Prograin Study document.

6. Prepare and issue 1?-102 Engine Summary Section. Prepare and issue approximately ten sample Verification Information Sheets based upon Engine DRB specification.

7. Prepare and issue Facility Performance Requirements Documents (T-134's) for ETS-1 based on an evaluation of Section 3 of the engine C-002 specification and preliminary development test requirements.

8. Perform the activities necessary to define the content and provide a plan to conduct Engine Demonstration PDR. Coordinate the activities necessary to define the content and conduct of component/subsystem Demonstration PDR. Provide a preliminary agenda and schedule for the conduct of the Demonstration PDR's. 


\section{PROJECT 116 - Continued}

n. Issue flight program FFD's (S-052), RAS's (S-053), SBD's (S-055), and TLS's (S-056) Blocks 1 thraugh 6 for Engine PDR.

2. Perform the necessary functional analysis to accomplish the following Systems Engineering activities for the NERVA Ground Test Program:

a. Prepare and provide to SNPO preliminary FFD's (S-052).

b. Prepare preliminary RAS's (S-053) Blocks 6, 5, 4, 2 and 1.

c. Prepare final FTD's (S-052) to support Demonstration PDR in $\mathrm{CY} 71$.

d. Deleted.

e. Prepare and transmit the input to the preliminary Reactor Ground Test RAS's (S-053).

f. Prepare the input to the Final Reactor Ground Test RAS's (S-053) to support Demonstration PDR in CY 71.

3. Perform engineering support activities to accomplish the following:

a. Evaluate engine requirements specified in tre NPRD or generated by other sources such as stage integration activities.

b. Review and approve all issues of the NERVA Engine Specification.

c. Complete the design/trade studies 027, Structural Support Cooling Subsystem and complete the analysis, less engine transient, for Trade Study 201 - Pressurization Gas Requirements in support of Engine PDR.

d. Provide engineering support input to other trade studies as required. 


\section{PROJECT 116 - Continued}

e. Develop and provide ground and flight operations data to the various NERVA Program participants as required.

f. Develop a prototype system effectiveness mathematical model which can provide the framework for making cost effectiveness decisions of alternate engine configurations and program concepts. The following types of parameters shall be evaluated in building the prototype system effectiveness model:

(1) NERVA/shuttle traffic model parameters, such as total payload, number of vehicles, number of engines, number of EOS's and number of EOS flights, etc.

(2) Logistics operation parameters (e.g. maintenance tugs, maintenance depots, personnel, spares inventory and location, and time allocations, etc.) for selected maintenance concepts.

(3) Vehicle and engine performance parameters such as useful life, engine $I_{S p}$, engine and vehicle weights, reliability, etc.

The prototype model shall have provisions to include the above parameters even though data to input the model may not be available. Unavailable input data will have to be developed in the future.

4. a. By utilizing good engineering judgment, establish maintainability, maintenance, and support ground rules and concepts for the engine ground test program, ground phase of the engine flight program, and flight phase of the engine flight program.

b. Prepare Block 8.0 functional analysis based on the ground rules and concepts established in paragraon 4.2 for the ground phase of the engine rlight program and publish for engine PDR.

c. Deleted 


\section{PROJECT 116 - Continued}

Deleted.

(D)

$-22 A-$ 
Suffix $f$ - Development Engineering

1. Provide the lead technical liaison and project coordination within NRO and with WANL, NTO and SNPO as necessary to provide definition and control of the following interfaces:

a. Engine/Vehicle

b. Engine/Test Facility

c. Reactor Test Assembly/Test Facility

d. Engine, Subsystem and Components/AGE

e. Engine Nuclear Subsystem/Engine Non-Nuclear Components and Subsystems

f. Between Engine Non-Nuclear Components

This general responsibility is reflected in the following specific work statements during CY 1970:

2. Prepare a preliminary Data Item E-106 for Engine Design PDR. The following ICD's shall be included:

a. NERVA Flight Engine ICD defining interfaces between the engine and stage and between the engine, subsystems and components and operational AGE.

b. NERVA Nuclear/Non-Nuclear ICD defining interfaces between the NSS and non-nuclear subsystems and components of the flight engine.

c. NERVA Non-Nuclear Component ICD defining interfaces between non-nuclear components of the flight engine.

3. Deleted.

4. Provide support to the AGC Change Board (ACB) activities.

5. Prepare an MRI for the NERVA Flight Engine. This effort includes the following activities and supports DRB, and Engine Design FDR:

a. Define the requirements for MRI inputs.

b. Review and approve the MRI inputs.

c. Prepare a preliminary MRL for the enzine configuration presented at "Conceptual Engine PDR."

d. Prepare a preliminary draft of an MRI for the PDR Engine.

6. Initiate preparation of preliminary AGC input to the preliminary Reactor Ground Test MRL that is issued by WANL. 
Rev. $7-7-70$

PROJECT 117 - Continued

7. Initiate preparation of a preliminary Non-Nuclear Component Layout drawing to support the preliminary Reactor Test Assembly drawing prepared by WANL.

8. Initiate a preliminary issue of Data Item E-106 (NERVA Ground Test Nuclear Subsystem Non-Nuclear ICD) defining interfaces between the ANSC and WANL hardware.

9. Prepare preliminary Data Item E-106 (NERVA Ground Test Engine ICD) defining interfaces between the engine and test facilities and between the engine, subsystem and components and associated AGE listed in Projects 205, 206 and 207. 
PRO.JECT 118 - SYSTEY SHIELDING ANALYSIS

Suffix b - Techlology Engineering

1. Prepare final draft copy of report on XE-P radiation analysis.

2. Prepare final draft copy of XE-P dosimetry report.

Suffix $f$ - Development Engineering

1. Maintain, issue and update Common Radiation Analysis Nodel of the flight configuration of the NERVA. Propulsion Module consisting of the representation of the engine, propellant tank and pajload with the representation of the Iiuclear subsystem provided by WANL.

2. Participate in the systems engineering process to the level necessary to establish and expand, as appropriate, the allowable radiation environment requirements for the payload, $S / N$ stage, the CEI's, the critical components and other components.

3. Perform analyses of the after-shutdown radiation environment with and without the disk shields. Define maintainability shield requirements.

4. Complete Shielding Trade Study (T. S. 023).

5. Prepare final Shielding Trade Study Report (Data Item S-054).

6. Establish the requirements for the internal shield.

7. Calculate the magnitude and distribution of radiation and/or radiation heating throughout the engine system (exclusive of the Nuclear Subsystem), the propellant module and the payload.

8. Study the shielding requirements for the remainder of the engine, and in the remainder of the nuclear stage and payload.

9. Provide nuclear analysis support for engine test facilities in support of Data Item S-100. This effort shall be documented in Data Item S-054 for T. S. 1015 which shall be completed in CY 1971.

10. Perform nuclear radiation and shielding analysis of steady (C) state and shutdown environments for Data Item S-100 to be issued in CY 1971. 


\section{PROJECT 118 - Continued}

11. Develop, improve and evaluate analytical methods to be used in system shielding analysis. Coordinate with WANL on similar methods development activities.

12. Investigate alternative approaches such as propellant tank L/D variations, and propellant tank shapes, as they relate to shield weight with the objective of minimizing overall nuclear stage weight. Prepare and issue a report.

13. Perform nuclear and radiation analyses to support planning for the NERVA Mission Applications. These should include analyses of typical payloads and rendezvous and docking rediation patterns and shielding requirements. Perform Monte Carlo analyses where required.

14. a. Conduct Monte Carlo analysis of the nuclear stage and selected payloads including Monte Carlo computations of the payload radiation attenuation factors.

b. Initiate a report to be completed in CY 1971 .

15. Provide radiation and shielding analysis support to the stage contractors.

16. Prepare reports on computer code developments and analytical technique developments and applications. Submit reports and computer code packages on codes of general interest to the Radiation Shielding Information Center.

17. Perform nuclear design of the external engine shield subsystem.

18. Provide preliminary estimates of the radiation environment of components in E-1 test in ETS-l.

19. Provide preliminary estimates of the radiation environment of non-nuclear components in R-I test in Test Cell " $\mathrm{C}$ ".

20. Provide technical and programmatic direction and review of WANL shielding projects.

21. Investigate alternative replaceable shielding concepts, including the use of alternate materials, and provide recommendations to support Project 112 efforts in developing replaceable shield concepts. 
Sufix $f$ - Development Eng:-reering

1. Provide the engineering support necessary to assure satisfactory integration between NERVA engine, subsystems and components. Continuously evaluate the engine, subsystem and component rerequirements and design.

2. Prepare, issue and maintain Trade Study Index.

3. Scope, coordinate and evaluate all trade and design studies (S-054) identified through the work program.

4. Prepare Part I of the Engine CEI Specification as follows:

a. Preliminary C-002, Sections 1, 2, and 3 .

b. C-002 for DRB, Sections 1, 2, 3, and preliminary 10 .

c. Revised Preliminary C-002 Sections 1, 2, 3, 6 and 10.

5. Develop requirements for engine specifications for Sections 1, 2, 3, 6 and preliminary Section 10. These requirements shall be issued in the design requirement sheet.
a. Preliminary

b. First revision for $D R B$

c. Complete update for DRB

d. Transient analys is update

6. Develop, maintain and control requirements for Sections 3,6 and 10 of subsystem and component specifications. These requirements shall be issued and controlled through design requirement sheets and supplements.

7. Prepare, issue and maintain the S-023, NERVA Engine Natural Environment Report.
a. Preliminary
b. Final

8. Provide representation and support to the NERVA Environmental Loads Committee. 


\section{PROJECT 119 - Continued}

9. Establish, maintain and control the NERVA reference

engine state points and data used to establish design.

10. Review and approve subsystem and component specifications. 
1. Complete PFS Trade Study No. 101 and Turbopump Trade Study No. 102 to scope as defined by $7740: 10410$; specify turbopump concept, PFS schematic, predicted performance of selected system in informal report.

2. Release drawings for vibration test rotor and stator blades.

3. Specify and issue informal report on materials property data required for turbopump design. Specify envirormental conditions.

4. Complete and issue informal report covering initial performance prediction/behavioral analysis at 3 sigma specification extreme conditions from C-002 Specification, Revision 2, for normal mode steady state, malfunction mode steady state, one throttle steady state.

5. Deleted.

6. Release drawings for test hardware for flow/performance air tests of turbine housings.

7. Release drawings for $60 \mathrm{~mm}$ roller bearings.

8. Complete initial failure mode analyses.

9. Define TPA development plan including subcomponerts not previously covered. Publish an informal report.

10. Define TPA facility and STE requirements. Publish AGC informal report.

11. Support engine design on level of effort basis.

12. Provide planning support and documentation on level of effort basis. 
13. a. Select thrust kalancer concept (integrated vs. separate); publish analysis as AGC informal report; incorporate on layout.

b. Start drawings for Pump LH2 suction performance test hardware.

c. Start drawings for Pump Air Test hardware.

14. Select shaft leakage control devices (seal vs. labyrinths); publish analysis as AGC informal report; incorporate on layout.

15. Deleted.

16. Prepare input for TPA chapter of Data Item E-105, consisting

of the following:

a. "A" change TPA layout drawings which incorporate results of all design, analysis and testing performed as of september 1, 1970.

b. A narrative design selection justification, which shall discuss in detail the basis on which the design of the TPA and its components were selected as of Septeriber 1, 1970 to satisfy the specification requirements.

c. A one-dimensional analysis of all major flow passages and blade shapes.

d. Issue informal 7700 report.

17. Prepare and issue the Part I TPA Specification Data Item C-002 as follows:

a. Initial issue, which contains Sections 1,2 and 3 TPA requirements based on initial reference engine analysis data available as of December 1, 1969.

b. Revision No. 1 which will consist of Section 6 and a Section 3 updated to include requirements resulting from revised engine analysis, based on reference engine, which has been updated to include major trade study decisions. Obvious Section 10 requirements will be included.

c. Revision No. 2 for $\mathrm{DRB}$ which will reflect impact of Change Orders $70-8$ and $70-14$.

\section{d. Freliminary Section 4}

18. Prepare and issue Data Item S-054, Requirements/Design Trade Study Report, consisting of the following: 
a. Propellant Feed System Trade Study Report 101 and

Turbopurn Trade Study Report 102. This report shall include $\equiv$ aiscussion of all systems considered, a summary of analyses performed, the parameters against which the systems were compared and the basis by which the propellant feed system and turbopump concept were selected.

19. Conduct TPA Thermal Analysis for S-03I consisting of the following:

a. Steady.state thermal analysis of turbine rotor discs and blades, turbine stators, impeller discs and blades, inducer disc and blades, as affects stress; and bearing cartridges, thrust balancer pump and turbine housings as affects fits or deflections.

b. The input data shall be based upon:

(1) Flight spec extreme steady state conditions from C-002 Specification, Revision 2.

(2) Turbopump layout, "O" change.

(3) Estimated internal conditions.

(4) Nuclear dose rate from C-002 Specification, Revision 2.

(5) Deleted

(6) Deleted

c. Issue informal 7700 report.

20. Conduct TPA Stress Analysis for S-036, consisting of the following:

a. Stress Analysis of turbine rotor discs and blades, impeller discs and blades, inducer discs and blades, and turbine stators; deflection analysis of pump housings.

b. The input data shall be based upon:

(1) Flight spec extreme steady state conditions from C-002 Specification, Revision 2. 
PROJECT 121 - Continued

(2) Turbopump layout, "O" change.

(3) Analyzed thermal equilibrium temperature, including nuclear profiles at steady state from C-002 Specification, Revision 2 and Layout "O".

(4) Estimated transient thermal profiles.

(5) Analyzed inertia and pressure loads.

(6) Analyzed self-induced dynamic loads.

(7) Deleted.

(8) Deleted.

(9) Deleted.

c. Issue informal 7700 report.

21. Conduct TPA Dynamics Analysis for S-038 consisting of the following:

a. Dynamics analysis of rotor discs and blades, impeller discs and blades, inducer discs and blades and shaft critical speed, turbopump mounted to ground.

b. Estimate of turbopump mount stiffness requirements at interface.

c. Turbopump configuration definition for engine dynamic analysis.

d. The analysis shall be based upon:

(1) Flight spec extreme conditions from C-002 Specification, Revision 2.

(2) Turbopump layout, "O" change.

(3) Analyzed self-induced vibration.

(4) Deleted.

(5) Deleted.

e. Issue informal 7700 report. 


\section{PROJECT 121 - Continued}

22. Supply input for Loads Analysis for S-039 consisting of the following:

a. Turbopump layout, "O" change with estimated turbopump orizinated interface Ioads.

b. Deleted

23. Supply input for Mass Properties for $\mathrm{S}-047$ consisting of the following:

a. Turbopump assembly based on "O" change layout with selected materials defined.

24. Deleted

a. Deleted

25. Supply input to Radiation Iffects for S-110, consisting of the following:

a. Turbopump configuration definition (" $O$ " change layout) with estimated internal environments, and the selected materials.

26. Conduct Readiness Review for Phase IA Twin TPA $t$ sting at Test CelI "C".

27. Conduct TPA reliability analyses consisting of the following:

a. A preliminary failure modes analysis on the turbopump down to the part level. This analysis shall be based on turbopump layout "O" change.

b. A preliminary reliability allocation and assessment based on preliminary performance prediction.

c. Issue informa1 7740 report.

28. Prepare TPA initial systems analyses summary report consisting of the following:

a. Prelininary turbopump performance prediction for specification extreme conditions for normal mode steady state, one throttle mode steady state.

b. The analysis shall be based upon:

(1) Flight specification extreme conditions from C-002 Specification, Revision 2.

(2) Turbopump layout "O" change.

(3) Issue informal 7740 report. 


\section{PROJECT 121 - Continued}
a. Deleted
b. Deleted

(1) Deleted

(2) Deleted

(3) Deleted

29. Release drawings for bearing tester modifications for 65 or $70 \mathrm{~mm}$ roller and ball bearings.

30. Complete and publis sections 1, 2, 3, 6, and preliminary 10 of the FFS C-OO2 Specification.

31. Complete and publish PFS C-002 Specification, Part I Sections $1,2,3,6$, and preliminary 10, Revision No. 2 to reflect impact of Change Orders $70-8$ and $70-14$.

32. Complete and publish PFS C-002 Specification, Part I, Preliminary Section 4.

33. Prepare and submit a test plan for conducting a Dual TPA Test Series at Test Cell " $C$ " vith the objectives of investigating questions of systens dynamics, performance and control of a turbine bypass system during the vario'ds phases and modes of engine operation for the full flow cycle.

\section{Suffix $g$ - Development Testing}

1. Deleted

2. Deleted

3. Start tests on $60 \mathrm{mn}$ tanjem ball bearing; detarmine dynamic spring rate.

4. Deleted

5. Start tests of $60 \mathrm{im}$ tandem ball bearings with Armalon cages. 
PROJECT 121 - Continued

6. Deleted.

7. Start tests of $50 \mathrm{~mm}$ roller bearings with prototype material cages.

8. Start tests of $50 \mathrm{~mm}$ ball bearings with irradiated prototype material cages.

9. Start tests of $50 \mathrm{~mm}$ roller bearings with irradiated prototype material cages.

\section{Suffix i - Development Fabrication}

1. Initiate fabrication of rotor and stator blade, vibration test articles and fixtures.

(C)

2. Initiate fabrication of hardware for flow/perior.llance air tests of turbina housings.

3. Initiate fabrication of 65 or $70 \mathrm{~mm}$ roller and ball bearings.

4. Initiate fabrication of bearing tester modifications for 65 or $70 \mathrm{~mm}$ roller and ball bearings.

5. Deleted.

6. Initiate fabrication of Pump LH2 suction performence test

7. Initiate fabrication of Pump Air Test hardware. 
Rev. $7-7-70$

PROJERT 122 - ENGINE VALIES (BINARY) AIND ACTUATORS

Suffix b - Technology Engineering

1. Complete the applicable valve sections of the XE data analyses report, Volume III of the Final Test Report.

2. Direct post-test examination and disassembly of the XE valves, PSV, TBV, PDSV, CVV and PDKV to obtain design information and to verify the source of anomalies experienced during the XE test program. Report results in an internal AGC memorandum two (2) months after completion of post-test examination.

Suffix $f$ - Development Engineering

Two position valves and associated actuators included in this project are:

Group (A) - Those unchanged by selection of the S-3 Engine Flow Schematic and (B) - Those added or changed significantly by that selection. Group (A) consists of the Propellant Shutoff Valve (PSOV), the Trurbine Block Valve (TBV), and the Cooldown Shutoff Valve (CSOV). Group (B) consists of the Pump Discharge Block Valve (PDBV), the Turbine Discharge Block Valve (TDBV), and the Bypass Block Valve (BBV).

1. C-002 Specifications

a. To support DRB, complete ía ita item C-OO2 CEI/CC Part I (Section 1, 2, 3, 6 and preliminary 10) specifications for Groups (A) and (B).

b. Complete a preliminary Section 4 of the Group (A) valves.

c. Complete data item C-002 CEI/CC Part I (Seciions 1, 2, 3 and 6) specification format draft for PSOV, TIV, and BBV.

d. Preliminary Section 4 for the Group (B) valves shall be in process.

2. Complete the preliminary concept selection of valve assemblies for the reference engine to support conceptual Engine PDR.

3. Simple failure mode analyses on the selected concepts for data item R-202, Reliability Allocations, Assessments and Analyses (Modes \& Mechanism only) shall be in process.

4. A preliminary layout (Data Item E-105-Engineering Data for Design Evaluation) which defines major part dimensions and materials will be completed for Group (A) valves and in process for Group (B) valves.

5. Complete Trade Study -032 and document results in data item S-054 Requirements/Trade Study Report. Complete an engineering draft of T. S. 103 excluding transient requirements for the valves. 


\section{PROJECT 122 - Continued}

6. The nuclear analysis input for data item S-100 Radiation and Shielding Analyses Report shall be in process. Complete steady state thermal analysis of critical CSOV parts. Complete preliminary thermal analyses. The preparation of thermal models for the Group (A) valves shall be in process. Preliminary thermal analysis of the Group (B) valves (S-03l Thermal and Fluid Analysis Report) shall be in process.

7. Provide engineering support for the valves used in Test Cell "C" TPA testing.

8. Conduct necessary design analyses to support the following trade studies:

a. 021 Engine System Rated Performance

b. O22 Post Shutdown Operations

c. 026 Startup and Shutdown Ramps and Throttleability and Chilldown

d. 101 Propellant Feed Subsystem

e. 103 Engine Valve

f. 419 Engine Electrical Power Supply Requirements

g. 420 Instrumentation and Control Subsystem

h. 422 Wiring Harness

i. 1003 Maintainability Inflight and Ground

j. 1004 Engine Acceptance Test

9. Preparation of the required input to the following data items to support Engine PDR shall be in process:

a. S-001 Systems Analysis Summary Report (Steady State)

b. S-038 Dynamic Analysis Report

c. S-039 Loads Report

10. Complete design of a new poppet seal concept.

11. Write a computer program. The analyses of preliminary transient response times, acceleration values, motor power and transient current requirements based on conceptual valve and actuator designs for Group (A) valves shall be in process.

12. Preliminary stress calculations on conceptionally selected Group (A) actuator gear and bearing types based on valve inertias, mass, predicted acceleration values and preliminary thermal values shall be in process. Complete preliminary stress analysis. The intermediate stress analysis for CSOV shall be in process.

13. Establish preliminary motor size limits for actuator concept selections. 
PROJECT 12? - Continued

14. Prepare preliminary specification control dravings and preliminary specifications for procurement of motor test specimens.

15. Complete design of a motor test fixture for motor feasibility tests.

Suffix i - Develooment Fabrication

1. Complete fabrication of test hardware for the cortamination test program.

2. Procure electric motors, gear trains and test fixtures to support the design feasibility testing activity.

Suffix $g$ - Development Testing

1. Complete initial contamination test.

2. Complete preliminary ambient and IN2 leak and cycle tests of gold-plated metal lipseal designs.

3. Conduct initial feasibility test on electric motors and determine the dynamic motor characteristics.

4. Determine initial motor efficiencies. 
Analog valves and associated actuators included in this project are Group (A), those unchanged by selection of the S-3 Engine Flow Schematic on May 14, 1970, and (B) those added or chenged significantly by that selection.

Group (A) consists of the Cooldown System Control VaIve (CSCV).

Group (B) consists of the Pump Discharge Valve (PDV), the Turbine Throttle Valve (TTV), and the Bypass Control Valve (BCV).

Suffix $f$ - Development Engineering

1. C-002 Specifications.

a. Complete data Item C-002 CEI/CC Part I (Sections 1,2,3,6 and preliminary 10) specifications to support DRB for Groups (A) and (B).

b. Complete a preliminary Section 4 draft of the Group (A) valves.

c. Complete data item C-002 CEI/CC Part I (Sections 1, 2, 3, and 6) specification format draft for the BCV and CSCV.

d. Preliminary Section 4 for the Group (B) val.ves shall be in process.

2. Complete the preliminary concept selection of the valves and actuators for the reference engine to support Conceptual Engine PDR.

3. Simple failure mode analyses on the selected concept for data item R-202 Reliability Allocations, Assessments and Analyses (Modes and Mechanisms only) shall be in process.

4. A preliminary layout (data Item E-105 Engineering Data for Design Evaluation) which defines major part dimensions and materials, will be complete on the Group (A) valves and in process for Group (B) valves.

5. Complete an engineering draft (excluding transient requirements) of Trade Study No. 103 to be documented in S-054 Requirements/Trade Study Report for the valves.

6. The nuclear analysis input for data item $S-100$ Radiation and Shielding Analyses Report shall be in process. Complete steady state thermal analyses of critical CSCV parts. Preliminary thermal analyses of the Group (B) valves (S-03l Thermal and Fluid Analysis Report) shall be in process. 
PROJECT 123 - Continued

7. Conduct necessary design analyses to support the following trade studies:

a. 021 Engine System Rated Performance

b. 022 Post Shutdom Operations

c. 026 Startup and Shutdown Ramps and Throttleability and Chilldown.

d. 032 Actuator Drive Power

e. 101 Propellont Feed Subsystem

f. 103 Engine Valve

g. 419 Engine Electrical Power Supply Requirements

h. 420 Instrumentation and Control Subsystem

i. 422 Wiring Harness

j. 1003 Maintainability Inflight and Ground

k. 1004 Engine Acceptance Test

8. Preparation of the required input to the following

data items to support Ingine PDR shall be in process:

a. S-001 Systems Analysis Summary Report (Steady State)

b. S-038 Dynamic Analysis Report

c. S-039 Loads Report

9. Write a computer program. The analyses of preliminary transient response times, acceleration values, motor power and transient current requirements based on conceptual valve and actuator designs for the Group (A) valve shall be in process.

10. Definition of preliminary transient and frequency response characteristics of the control loop kased on conceptual Group (A) valve and actuator designs shall be in process.

11. Determine preliminary electric motor requirements for the CSCV.

12. Deleted.

13. Complete design of CSCV contamination test fixture.

14. Initiate and maintain in process preliminary stress calculations on conceptually selected Group (A) actuator gear and bearing types based on valve inertias, mass, predicted acceleration values and preliminary thermal values. 


\section{PROJECT 124 - EIGIIE CHECK VALVE}

The Valves includec in this project are the Pump Discharefe Check Valve (PDKV) and Turbine Discharge Check Valve (TDIV).

\section{Suffix $f$ - Develooment Engineering}

1. C-002 Specifications

a. Complete data item C-002 CEI/CC Part I (Sections I, 2, 3, 6 and preliminary 10) Specifications to support DRB Which include the requirements for the PDKV and IDKV.

b. Complete a preliminary Section 4 for the PDKV and TDKV.

c. Complete data item C-002 CEI/CC Part I (Sections 1, 2, 3 and 6) specification format draft for the PDKV.

2. Complete the preliminary selection of the valves for the reference engine to support Conceptual Engine PDR.

3. Complete simple failure mode analyses on the selected concepts and provide as input to data item R-202 Reliability Allocations, Assessments and Analyses (Modes and Mechanisms only).

4. Complete a preliminary layout (data item $E-105$ Engineering Data for Design Evaluation) of the final valve concept.

5. Complete an engineering draft (excluding transient requirements) of Trade Study No. 103 to be documented in S-054 Requirements/ Trade Study Report for the PDKV.

6. The nuclean analysis input Ior data item $S-100$ Radiation and Shielding Analysis Report shall be in process. Complete steady state thermal analysis of the critical PDKV parts (S-031 Thermal and Fluid Analysis Report).

7. Conduct necessary design analyses to support the following trade studies:

a. 021 Engine System Rated Performance

b. 022 Post Shutdown Operations

c. 026 Startup and Shutdown Ramps and Throttleability and Chilldown

d. 032 Actuator Drive Power

e. 101 Propellant Feed Subsystem

f. 103 Engine Valve 
PROJECT 124 - Continued

g. $\quad 420$ Instrumentation and Control Subsystem

h. 419 Engine Electrical Power Supply Requirements

i. 422 Wiring Harness

j. $\quad 1003$ Maintainability Inflight and Ground

k. 1004 Engine Acceptance Test

8. Preparation of the required sections of the following data items to support Engines PDR shall be in process:

a. S-001 Systems Aralysis Summary Report (Steady State)

b. S-038 Dynamic Analysis Report

c. S-039 Loads Report

9. Preparation of a computer program and analyses of preliminary transient response times, acceleration values, motor power and transient current recuirements based on conceptual ralve and actuator designs shall be in process.

10. Preparation of preliminary stress calculations on conceptually selected actuator gear and bearing types based on valve inertias, mass, predicted acceleration values and preliminary thermal values shall be in process. 
Rev. $7-7-70$

PROJECT 127 - MAJOR LIT.ES

This project includes the Turbine Inlet Lines, Turbine Discharge Iines, Propellant Inlet Line, Turbine Eypass Iine, Cooldomn Iine, and Structural Support Coolant Lines, and Pump Discharge Lines.

Suffix $f$ - Development Engineering

1. E-105 - Support the engine configuration packaging and maintainability activities by supplying line drawinss. These drawings will define line dimensions, materials, weights, and pressure loss coefficients in support of the reference engine.

2. S-001 - Supply all final line diameters and loss coefficients as necessary for engine system analysis.

3. $\mathrm{C}-002$

a. Prepare and release Component Specifications, Sections 1, 2, 3, 6 and preliminary 10 to support DRB. Update these documents as required throughout the year to include current engine requirements.

b. Complete a preliminary Section 4 .

c. Complete data item C-002 CEI/CC Part I (Sections I, 2, 3 , and 6) specification draft for the lines.

4. R-202 - Complete FMA to the following extent: Identify PIL failure modes and mechanisms and establish preliminary failure probability rates, exclusive of those induced by maintainability-related activities. Complete an item description and listing of failure modes for the TIL, TDL, TBI, CL, SSBL, SSCL, and PDI.

5. S-038 - Complete modal analysis of PDL for the December (1969) Reference Engine. Complete input of line coordirates and properties for modal analysis of the PDL, TIL, and TDL for the June (1970) Reference Engine.

6. S-03I - Complete determination of heatup rate for stagnant TDL for December (1969) Reference Engine. Submit data as necessary for a similar analysis of all stagnant lines for the June (1970) Reference Engine. Submit three designs of FDL/nozzle joints for determination of temperature distribution.

7. S-039 - Definition of all line interface loads except those due to vibration shall be in process. 
PROJECT 127 - Continued

9. S-047 - Provide line mass data input.

10. S-054 - Initiate the Category "C" portion of Design Trade Study $\mathbb{N}$. 104 as follows:

a. Identify material candidates.

b. Identify joint, coupling, and seal candidates.

c. Identify maximun bellows movements for one type of valve support for the June (1970) Reference Engine PDL, TIL, TDI, and TBL.

d. Identify three types of valve supports for bellows and/or non-kellows line configurations.

11. S-100 - Initiate determination of heat generation rates.

\section{Suffix g - Development Testing}

1. Conduct testing to obtain preliminary test data on static seals.

a. Select candidate seals and couplings for an initial procurement package and place purchase order for these units.

b. Complete fabrication of seal and coupling tester.

c. Begin tests and obtain preliminary data.

2. Develop line automatic weld machines and procedures.

a. Evaluate preliminary equipment demonstration by two subcontractors using aluminum and Inconel 718 tubing of approximately PDL diameter.

b. Write detailed test program based upon the above equipment demonstration.

c. Place purchase order for veld development. 


\section{PEOJECT 131 - PURGE AND PRESSURTZATION COMPOI:EYTS}

Tinis project jncludes the engine purge unit (EPU) and the stage tank pressurization line and check valve (SPLA).

Suffix $f$ - Development Engineering

1. Complete engine purge unit parametric study to define interrelationship between System Delta $P$, flow rates and line sizes. Report results in internal AGC memoranda.

2. a. Complete preparation of C-002 CEI/CC/DS Part I Specification (Sections 1, 2, 3, 6 and preliminary 10.)

b. Complete a preliminary Section 4.

c. Complete dat a item C-002 CEI/CC Part I, (Sections I, 2, 3 , and 6) specification draft for the EPU and SPLA.

3. Complete preliminary sub-component specifications

4. Preliminary (E-105) Concept Engineering Data for Design Evaluation. Initiate layout drawings of the engine purge unit lines and subcomponent and the stage tank pressurization line and subcomponents. Complete centerline routing of purge unit distrirution manifold and stage tank pressurization line. Complete preliminary sizing of subcomponents.

5. S-031 Thermal and Fluid Flow Analysis - Fluid flow analysis to determine system line and subcomponent sizes shall be in process. Complete evaluation of assumptions used to deterrine purge duration and flowrate.

6. S-100 - Radiation and Shielding Analysis - Complete selection of materials to be used for fabrication of the EPU and SPLA to allow initiation of nuclear environment definition.

7. S-110 - Radiation Effects Analysis - Complete definition of materials to be used for fabrication of the EPU and SPIA to allow initiation of radiation effects analysis.

8. S-054 - Requirements/Trade Study Report. Design concept selection trade study reports documenting the results of the concept selection study (Trade Study No. 1013) shall be in process. Complete determination of purge duration and flowrate and definition of interface locations.

9. Conduct necessary design analyses to support the following trade studies:
a. 032 Actuator Drive Power
b. 201 Pressurization Gas Requirements
c. 1003 Maintainability Inflight and Ground
d. 1004 Engine Acceptance Test 
PROJECT 131 - Continued

e. 419 Engine Electrical Power Supply Requirements

f. 420 Instrumentation and Control Subsystem

g. 422 Wiring Harness

10. Deleted

(D) 
Suffix $f$ - Development Engineering

1. Quantify the nozzle design problems related to chamber pressure, complete analyses, present results and recommendations to SNPO-C and prepare $\mathrm{P}_{\mathrm{C}}$ Trade Study report input to support Conceptual Engine PDR.

2. In support of an independent analysis, provide to SNPO-C nozzle dimensions, temperature distributions, heat fluxes and material properties of specimens tested at Oak Ridge Laboratories.

3. Design low cycle thermal fatigue test specimens, prepare test plan and relsase fabrication drawings.

4. Complete fabrication of 12 Nozzle "U" Channel bending specimens per sketch included in Change Order 70-17.

5. Complete nozzle braze evaluation program; publish a report.

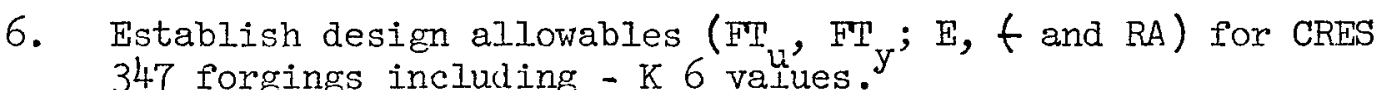

7. Place purchase order for CRES 347 sheet stock testing to obtain design allowables early in CY 1971.

8. Complete coolant channel design and input final design to Systems Engineering for inclusion into the S-001 data item.

9. Complete a nozzle assembly layout based on reference engine and upgrade as necessary to support the reference engine design.

10. Upgrade and publish Sections 1, 2, 3, 6 and a preliminary 10 of the Nozzle Assembly Subsystem C-002 Specification to support DRB.

11. Upgrade and publish Sections 1, 2, 3, 6 and a preliminary 10 of the Nozzle C-002 Specification to support DRB.

12. Complete Section 4 and preliminary Section 10 of Nozzle Assembly Subsystem C-002 Specification. Update Section 3 to include engine transient analysis results.

13. Complete Section 4 and preliminary Section 10 of Nozzle C-002 Specification. Update Section 3 to include engine transient analysis results.

14. Comolete vibration and static loads definition for nozzle area ratios 29:1 and 100:I at separated flow conditions in support of the requirements specified below: 
PROJECT 141 - Continued

a. An estimate of expected engine nozzle throat area, ratio, and contour with possible maximum and minimum values.

b. A determination of the need to flow the engine exhaust nozzle full during tests at chamber pressures in the range of 150-200 psia. This determination should be made on the basis of both structural and cycle thermodynamic evaluations.

c. Evaluate the desirability of testing the full cryogenically cooled nozzle at TC " $C$ " as compared with a low area ratio nozzle plus skirt simulator.

15. a. Conduct design, thermal, fluid, stress, fabrication and vibration analyses as necessary to determine whether a one or two piece nozzle/skirt will be required.

b. Publish report.

16. Develop gas side contour, determine nozzle throat size and conduct weight trade studies to optimize the terminal area ratio of the flight nozzle.

17. Predict nozzle assembly thrust and $I_{\text {op }}$ over the entire range of engine operating conditions and transmit this data to systems Engineering for inclusion to update Data Item S-OOL. (Preliminary assessments only.)

18. Using $\Delta \mathrm{P}-\Delta \mathrm{T}_{3}$ and weight sensitivity values from Systems Engineering, complete a study to determine the optimum terminal area ratio of the cryo cooled nozzle/skirt.

19. If a two piece nozle/skirt is required, analyses will be conducted to optimize the joint location of the nozzle/skirt interface.

20. Complete the nozzle and nozzle assembly FirECA's (based on qualitative evaluation only), establish reliability goals and transmit this information to the Reliability Section for inclusion in the R-202 data item, exclusive of quantitative treatment of stress-strength relationship and failure effects.

21. Conduct nozzle and nozzle assembly stress analyses (all primary stresses at steady state conditions as necessary to support design selection) for inclusion in Data Item S-036.

22. Complete design and fabrication studies on variable wall thickness and solit tube coolant channel designs in order to select coolant channel design and wall thickness. 
23. Conduct fabrication and design studies to determine least cost method producing NCX, WLilU and simulator nozzles, exclusive of drawing release.

24. Complete the bolt coolant system trade study, including report publications, to e.itablish the nozzle bolt coolant system and number of bolts.

25. Complete nozzle and nozzle assembly layouts and instrumentation dravings for inclusion into Data Item E-105.

26. Prepare input to Data Item S-031 consisting of the following:

a. Coolant channel wall temperature profiles, nozzle fluid conditions at steady state.

b. Jacket thermal analysis at steady state.

c. Equations used will be stated without technical dissertation.

27. Perform nozzle and nozzle assembly dynamic modal analysis for S-038 Data Item. Nozzle assembly vibration environment will be established.

28. Determine nozzle and nozzle assembly steady state loads analysis for Launch Vehicle Operation and Nuclear Space Operation (for full power) for Data Item S-039.

29. Complete S-047 Data Item except final weight rerision.

30. Complete nozzle heating rates for inclusion into $\mathrm{S}-100$.

31. Complete the Nozzle Assembly Trade Study (TS-301) and publish report.

32. Nozzle forging fabrication drawings shall be in process, (release for information only).

33. Make nozzle material selection and transmit decision for inclusion into Data Item $S-110$.

34. Calculate derating factor for area ratio $70: 1$ to 140:1 steady state conditions. 
35. Complete activities necessary to re-examine the effect of the tungsten hot-end support on nozzle heat transfer.

36. Complete a trade study to determine whether an oval or U-tube type construction should be used for the divergent section of the nozzle.

37. Investigate the feasibility and desirability of shortening the nozzle barrel length, including inrestigation of thermal effects.

38. Conduct design studies as necesary to improve the nozzlereflector seal to provide redundancy and eliminate the possibility of core lift off.

39. Determine the nozzle cooling feasibility with coolant flow rate fluctuating between SOL and EOL including malfunction and throttling modes of operation. Compare the above with nonvariable nozzle flow system. (Updated IJETAP S-3 flow schematic).

40. Complete an analys is to determine the nozzle thermal effects of opcrating a 24: $L$ nozzle in the " $R$ " test series without the use of an ejector duct. 
PROJECT 142 - Continued

b. Flange thermal analyses at steady state and critical conditions during transient operation.

c. An explanation of the method used to arrive at the temperature.

7. Complete and publish Sections I, 2, 3, and 6 of the C-002 Part I Nozzle Skirt Specification.

8. Complete Section 4 and preliminary Section $100 \vec{i}$ the C-002 Part I Nozzle Skirt Specification. Update Section 3 to include results of engine transient analysis.

9. Conduct skirt stress analyses (all primary stresses at steady state conditions; secondary and primary stresses for critical modes or as necessary to support the design selection) for inclusion in Data Item S-036.

10. Complete skirt heating rates for inclusion into Data Item S-I00.

11. Complete redesign of the R-skirt contour.

12. Complete FMECA to include effects and qualitatire evaluation of stress, thermal, quality control and materia?s for input to R-202 (exclusive of failure probability estimate).

13. Perform skirt dynamic modal, environmental criteria and steady state response analyses for Launch Vehicle Operation, Nuclear Space Operation ar:d Ground Test Conditions for S-038 Data Item.

14. Determine skirt steady state loads analysis for Iaunch Vehicle Operation and Nuclear Space Operation (for full power) for Data Item S-039.

15. Complete S-047 Data Item except final weight revision which will be made early in C'Y 1971.

16. Make skirt material selection and transmit decision for inclusion into Data Item $\mathrm{S}-110$.

17. Conclude all effort under this project effective March 23, 1970 as directed by Change Order 70-8. 
Suffix $f$ - Development Engineering

1. Perform the engineering activities required to produce the preliminary design of the graphite nozzle extension and an alternate concept as stipulated below:

a. The nozzle extension shall be constructed of fiber-reinforced graphite.

b. A vigorous prograin and schedule shall be follored to produce a full-scale first article to establish feasibility as soon as possible. Material and process development shall be conducted in a parallel efiort.

c. All work on aluminum, cryogenically cooled skirt extensions shall be terminated. This includes work being done in shielding analysis.

d. A backup nozzle extension concevt shall be developed. Primary consideration should be given to metallic construction of conventional materials utilizing film cooling.

2. Prepare data items to aupport preliminary design review with a level of maturity as suated below:

a. C-002 Specification - Nozzle Extension

(1) Update Part I, Sections 1, 2, 3, 6, and prəliminary 10 to support DRB.

(2) Complete a preliminary version of Section 4 to support Engi.le PDR. Update Section 3 to include results of eigine transient analysis.

b. R-202 Reliability Allocations, Assessments and Analyses Report

Preliminary failure mode analysis will be completed

exclusive of quantitative evaluation.

c. E-105 Engineering Data for Design Evaluation

Concept design layout drawing will be completed for ground test ana flight skirt extension

d. S-031 Thermal and Fluid Analysis Report 
The effects of steady state engine operational mode will

be established for the reference nozzle extension.

e. S-036 Structural Analysis Report

The primary stresses will be identified for steady state engine operational mode.

f. S-038 Environmental Vibration and Acoustics Report

(1) Free vibration analysis for ground test and flight skirt extensions will be completed.

(2) Dynamic loads analysis for nuclear stage operation, and engine ground test conditions will be complete.

g. S-039 Loads Report

Static loads from launch vehicle operation, nuclear stage operation and ground test operation will be complete.

h. S-047 Mass Properties Status Report

The weight allocation analysis will be completed for the ground test and flight skirt extension.

i. S-054 Design Trade Study Report

(1) Complete and issue S-054 Trade Study Report of skirt extensions primery concept selection.

(2) A trade studr leading to selection of a beckup skirt extension design shall be initiated and the following elements of this study will be performed:

Issue concept layouts.

Select candidate materials.

Issue a preliminary output of steady state thermal analysis.

Issue a preliminary assessment of performance penalties. 
PROJECT 143 - Continued

j. Deleted.

3. Conduct design engineering activities for the fabrication of a feasibility demonstration unit and complete fabrication drawings considering four (4) fabric layup techniques: tape wrap, shingle lap, rosette and three dimensional weave. Consider also evaluation of variations in flange design.

4. Produce specifications for control of fabrication processes for the fabrication demonstration unit.

Suffix $g$ - Development Testing

1. Establish the non-destructive test procedures development plan for the graphite skirt extension and perform the engineering activities required to design specimens for evaluation of NDT processes. Produce fabrication drawings for INDT specimens.

2. a. Complete corrosion tests of graphite composite material in a high velocity high temperature hydrogen atmosphere.

b. Complete corrosion test evaluation and issue report.

\section{Suffix $h$ - Development Tooling}

1. Perform plant engineering activities for the installation of graphitization equipment and complete facility drawings.

2. a. Produce specifications for the graphitization equipment.

b. Place purchase order for graphitization furnace.

3. Perform engineering design activities for modification of existing AGC furnace facilities for the skirt extension carbonization process.

4. Complete the modification of existing AGC furnace facilities for skirt extension carbonization process. 


\section{PROJECT 143 - Continued}

5. Perform design engineering activities for tooling required for fabrication of the graphite skirt extension up to completion of the carbonization process and complete fabrication drawings.

6. Place purchase order for tooling required for fabrication of the graphite skirt extension up to completion of the carbonization process.

Suffix i - Development Fabrication

1. Procure long lead materials of construction for the fabrication feasibility demonstration unit. 
PRO.JECT 151 - INSTRUCTIONT AITD CONTROL SYSTMM

Suffix b - Technology Eraireering

1. General

Support and provide engine control system inputs to the data analysis report.

\section{Suffix $f$ - Development Engineering}

1. Provide project control and overall integration of the I\&C system in the areas of requirements derinition, interface coordination, program planning, scheduling and reporting of I\&:C activities. This includes coordination with Projects 152, 153, 155, 159, 227, 451, 751 and 828.

2. Define overall IRC system requirements, interfaces, intrafaces, power requirements, test requirements, and update the I\&C C-OO2 Specification, BC-90214, Part I (Sections 1, 2, 3, 6 and preliminary 10) to support DRB.

3. From material gererated from Projects 152, 153, 155, 156, 159, 45I, 751 and 828, prepare and update the following I\&C component specifications, Part I (Sections 1, 2, 3, 6 and preliminary 10) to support DRB:

$\begin{array}{ll}\text { BC-90179 } & \text { Engine Wiring Harness } \\ \text { BC-90177 } & \text { Engine Instrumentation } \\ \text { BC-90155 } & \text { EPIC } \\ \text { BC-677565 } & \text { RSS Instrumentation }\end{array}$

4. As of February 2, 1.970, proceed with the digital I\&C system as the reference I ic system concept. The digital system may include provisions for those special purpose functions which may be better performed by other than ditital means.

5. Update the I\&C development plan, including Design Study 420 and support trade studies to reflect the digital I\&C concept as the primary effort.

6. Integrate and redirect subordinate system concept studies from Projects 152, 153, 156, 159, 45I, 751 and 828 to reflect a dizital I\&C concept. Complete and submit S-054 data item as follows:

a. Rough draft available at Conceptual PDR. 
PROJECT 151 - Continued

TS-417 EPIC Development Requirerents

TS-418 Wiring Harness Requirements

TS-419 Engine Electrical Power Source Requirements

b. Rough draft to support Engine PDR -

DS-420 Instrumentation \& Control Subsystem

DS-756 Reactor Controls

DS-758 Nuclear Safety

Data Item S-102 Controls Analysis Report (Preliminary)

c. Publish Trade Studies 417,418 and 419 .

7. Integrate material generated from Projects 152, 153, 155, 159, 451, 751, and 828 and submit applicable inputs to other INERVA data item activities.

8. Generate a preliminary measurement plan for the ground test and flight engine to support DRB.

9. Generate a measurement plan for flight engine to support engine PDR.

10. Generate engine instrunentation measurement plan for use in conducting the reactor tests and provide to WANL. Review and approve the total WANL measurement plan for reactor tests.

11. Provide support in determining overall ground test and flight engine measurement requirements. Provide support for determining engine instrumentation requirements for reactor tests.

12. Integrate inputs from Projects 152, 153, 155, 156, 159, 451, 75I, and 828 and submit inputs to Engine Specification CP-90290 to support DRB.

13. Establish requirements for, integrate the results of multiplexer location study, and select the approach.

14. Provide support for coordination with MSFC for NERVA I\&C/Stage interface definition by participation in appropriate meetings as required.

15. Deleted. 
16. Review and comment on ADP documents to provide guidance to $A D P$ planners in providing systems capable of meeting measurement requirements.

17. Determine techniques to be employed in acquiring and processing data to satisfy flight and ground test requirements.

18. As a part of Design Study 420, perform the following:

a. Determine preliminary power requirements for the reference engine $\mathrm{DRB}$.

b. Update power requirements for the engine PDR.

c. Determine preliminary mission time baseline for the reference engine power system (DRB).

d. Update the mission time baseline for the engine power system (PDR).

19. In support of Trade Study 417 and Design Study 421 , determine the advantages and/or disadvantages of multiplexing sensor signals at a point below the propellant tank.

20. For each of the specifications listed in paragraphs 2 and 3 above, complete preliminary Section 4.

21. Coordinate inputs from WANL and other organizations and prepare specifications for a digital computer and peripheral equipment required for system's design and development at WANL and at Test Cell " $C$ " for the $R$ series tests. 
Suffix $f$ - Development Engineering

1. To support Conceptual Engine PDR, perform necessary engineering (Trade Study 418, Wiring Harness Requireren'ss), to make the wiring harness concept selection for engine update.

2. Complete final Trade Study 418 report.

3. Generate inputs for Wiring Harness Specification, EC-90179, Part I, Sections 1, 2, 3, 6 and preliminary lo a a contribute to the wiring harness portion of the engine specification and the I\&C subsystem specification for DRB.

4. To support engine PDR, complete Design Study 422, Wiring Harness, with the exception of final installation drawings and final report, but including the following:

a. Complete evaluation of interface and intraface engine and component conrectors.

b. Develop designs for remote engagement of connectors for the engine components.

c. Complete preliminary engine installation harness dravings and schematics.

d. Develop cable requirements and make preliminary selection of cable types for the wiring harness.

5. To support Fngine PDR, generate inputs to EC-90I79, Part I (viring Harness Specification Preliminary Section 4.

6. Provide preliminary engine layout harness drawings and typical schematics for Data Item E-105. 
Suffix b - Technology Engineering

1. Support XE post-test electrical checkout and prepare instrumentation portion of $\mathrm{XE}$ data analysis report.

Suffix f - Development Engineering

1. To support DRB, prepare Part I, Sections 1, 2, 3,6 and preliminary 10 input for Engine, I $\hat{c}$, an other component specifications as required.

2. To support Engine PDR, prepare input for Preliminary Section 4 of the engine, I\&C, and other component specifications as required.

3. As a part of the Design Study 423 - Ingine Instrumentation, perform and document the following:

a. Complete the pretest analysis of multilead thermocouples as a means of providing in-rlight checkout and make a recommendation for development of the concept.

b. Complete the pretest investigation of a multijunction thermocouple to measure thrust chamber gas temperature.

c. Complete the pretest investigation of a wire rope RTI to measure thrust chamber gas temeerature.

d. Complete the pretest investigation of the ise of remote versus local mounted pressure transducers.

e. Complete the pretest investigation of pneumatic multiplexing of pressure measurements.

f. Complete the pretest feasibility study for flight accelerometers.

g. Investigate and evaluate methods of in situ calibration of the engine transducers for both ground test and flight operations.

h. Document work accomplished on uni-junction high temperature T.C.

4. Prepare and publish Test Information Sheets (TIS), Section 3-b, for any CY 70 development testing of candidate transducers and systems as selected by the Trade Stuay 423 . 


\section{PROJECT 155 - EPIC DESIGN AND DEVELOP ENTT}

\section{Suffix $f$ - Development Engineering}

1. Prepare reference functional designs and controls concept drawings for Design study 420 as follows:
a. Startup
b. Normal Range (incluaing Throttling)
c. Shutdown
d. Cooldown
e. Thrust Vector Control
f. Engine Malfunction Detection (Selected)

2. Conduct design studies and analysis and provide necessary direction for computer analysis for the following reference designs for Design Study 420:
a. Startup
b. Normal Range (include Throttling)
c. Shutdown

3. Prepare and submit technical material for the Design Study Report 420 (S-054) and Controls Analysis Report (S-102) for item 2 above. The S-1J2 will include a selection of a valving concept from the propellant feed system trade study, the selection of a SSCV valving system from the structural support cooling subsystem trede study, some critical malfunctions, a control concept selected and controllability demonstrated for startup, shutdown and steady state conditions. Controllability will be evaluated against specific accuracy requirements within the limits of the model. Maturity of data item: Ei gine model definition data from computer runs and preliminary analysis shaIl be complete to establisin support for engine PDR.

4. Coordinate, review, approve, and integrate into Design Study 420 WANL-generated functional designs from Project 451 into the engine control functional designs.

5. Assist through May 30, 1970, in evaluating the advantages and disadvantages of multiplexing sensor signals at a point below the propellant tank.

6. In support of $\mathrm{DRB}$, provide input to the EPIC critical component specification, C-002, Part I, Sections 1, 2, 3,6, and prelimirary 10.

7. In support of Conceptual Engine PDR, conplete Trade Study 417, EPIC Envelope Requirements, and prepare a S-054 study report. 


\section{PROJECT 155 - Continued}

\section{Suffix $f$ - Continued}

8. In support of Component PDR, develop EPIC digital control and data processing equipment design concepts, self check and power conditioning and distribution concepts.

9. Identify digital control experiments for evaluation during "R" tests.

10. To support Ingine PDR, generate inputs to the Dart I, EPIC Specification, EC-90179, Preliminary Section 4. 


\section{PFO JFRT If 1 - MFTET STFUCTUPE SUESTSTEM}

\section{Suff'x- Treloment Engineer:ng}

1. To support $\mathrm{DRB}$, upgrade Sections $1,2,3,6$, and preliminary

10 of Data Item C-002 CEI/CC, Part I, Specification for the thrust structure subsystem.

2. To support Engine PDR, complete Section 4 of Data Item C-002 CEI/CC, Part I, Spesification for the thrust structure subsystem.

3. Comolete nreliminary design concent selection to surnort Concentual Fngine PDR.

4. Compleze nuclear analysjs to supnort the design conceot.

5. Comnleze steary state thermal analisis for Data Ttem S-031.

6. Comnlete preliminary stress analysis to support conrept selection.

7. Steady state analysis for Data Item $\mathrm{S}-036$ shall be in process.

8. Comnlete basic weights analysis (Data Item $\mathrm{S}-047$ ) for selected concent.

9. Comolete engineering ohase of the category " $\mathrm{C}$ " portion of the Thrust Structure Assembly report is 501 for jata Item S-054 (exclusive of report DES Study).

10. Upgrade Sections 1, 2, 3, 6 and preliminary 10 of Data Item C-002 for the unper thruist structure (UTS), and lower thrust structure (ITS).

11. Upgrade Section 4 of Data Item C-002 for the UTS and ITS.

12. Complete draft Thrust Structure Assembly FMA and estimate if the TSA's reliability goal can be met (Modes and Mechanisms onIy).

13. Complete preliminary lateral and axial stiffness input to update Data Item $\mathrm{S}-038$.

14. Make thrist structures materials selections and transmit decisions for inclusion into Data Item S-110. 
Suffix $f-$ Continued

15. Complete thrust structures heating rates for inclusion into Data Item S-100.

16. Complete Thrust Structure Assembly launch criteria to support Data Item S-038.

17. Complete a preliminary layout of the selected design concept (Data Item E-105).

18. Initiate and maintain in process the following effort:

a. The detailed design layouts of the selected concept (Data Item E-I05).

b. Transient thermal analysis for startup and shutdown conditions.

c. Transient stress analysis for startup and shutdown conditions.

d. ROM dynamic (vibration) analysis.

e. Fatigue analysis to support Data Item S-036.

f. Establishment of reliability goals (exclusive of numerical analyses) as input to Data Item R-202.

g. Loads data as input to $\mathrm{S}-039$. 


\section{PRO.TECT 162 - EXIERNAL SHIELD SUESYSTEM}

Suffjx f - Develorment Engineering

1. Upgrade Sections $1,2,3,6$, and preliminary 10 of the

2. Complete Section 4 of C-002 CEI/CC, Part I, Specification to support Engine PDR.

3. Complete orel'minary design concept selection.

4. Complete nuclear analysis to support the design concept.

5. Comolete stead: state thermal analys for Data Item S-031.

6. Complete nreliminar. stress analysis to support zoncept selection for Data Item $\mathrm{S}-036$.

7. Complete basic weights analis s (Data Item S-047) for selected conceot.

8. Comolete engineering phase of external shield deisign studi report to support Data Item S-054.

9. Complete shield assembly FMA and estimate if the shield assembl: reliability goal can be met (Modes and ifechanisms only).

10. Preliminary lateral and axial stiffness analys s shall be in process for subsequent inout into Data Item S-100.

11. be in process for subsequent input into Data Item S-038.

12. Complete a preliminary layout of the selected design concept (Data Item E-105).

13. Initiate and maintain in process the following effort:

a. The detailed design layouts of the selected concept (Data Item E-105) shall be in process.

b. Deleted

c. Steady state stress anaylsis shall be in process. 


\section{$\underline{\text { PROJECT } 162 \text { - Continued }}$}

Suffix $f$ - Continued

d. Deleted.

(D)

e. ROM dynamic analysis (vibration) shall be in process.

f. Deleted.

g. Effort to support Data Items S-03I, S-038 and S-039 shall be in process.

h. Establishment of reliability goals (exclusive of numerical analysis) as input to Data Item $\mathrm{R}-202$ shall be in process.

i. External shield materials selections for inclusion into Data Items S-100 and S-110 shall be in process. 


\section{PROJECT 163 - GIMBAL ASSEMBLY SUBSYSTEIV}

\section{Suffix $f$ - Develooment Engineering}

1. Complete Sections $1,2,3$ and 6 and preliminary 10 of the C-002 CEI/CC, Part I, Specification for the gimbal pivot to support DRB.

2. Complete Section 4 of the C-002 CEI/CC, Part I, Specification for the gimbal pivot to support Engine PDR.

3. Complete preliminary design concept selection to support Conceptual Engine PDR.

4. Complete nuclear analysis to support the final design concept.

5. Complete steady state thermal analysis for Data Item S-031.

6. Complete preliminary stress analysis to support concept selection.

7. Complete steady state primary stress analysis for Data Item s-036.

8. Complete basic weights analysis (Data Item S-047) for the preliminary concept.

9. Complete a draft of the Category "C" portion of Gimbal

Assembly Trade study Report TS-031 for Data Item S-054. preliminary 10 data item $\mathrm{C}-002$ for the gimbal actuator to support $\mathrm{DRB}$.

b. Complete Sections 1, 2, 3, 6 and preliminary 10 Data Item C-002 for the gimbal actuator to support DRB.

11. Complete Section 4 of the Data Item C-002 for the gimbal actuator to support Engine PDR.

12. Complete Gimbal Assemblies FMA and estimate if the Gimbal Assemblies reliability goal can be met. (Modes and Mechanisms only).

13. Complete preliminary lateral and axial stiffness input to Data Item S-038.

14. Complete Gimbal Assembly heating rates for inclusion into Data Item S-100. 
PROJECT 163 - continued

15. Complete a preliminary layout of the selected design concept (Data Item E-105).

16. Initiate and maintain in process the following effort:

a. Gimbal Assembly launch criteria to support Data Item S-038 shall be in process.

b. A detailed design layout (Data Item E-105) of the selected concept shall be in process.

c. Transient themal analysis for startup and shutdown conditions shall be in process.

d. Transient stress analysis for startup and shutdon conditions shall be in process.

e. ROM dynamic (vibration) analysis shall be in process

f. Stress and fatigue analys is to support Data Item $\mathrm{S}-036$ shall be in process.

g. Establishment of reliability goals (exclusive of numerical analysis) as input to Data Item $\mathrm{R}-202$ shall be in process.

h. Effort to support Data Items S-031, S-038 and S-039 shall be in process.

i. Gimbal Assembly materials selections for inc usion into Data Item $\mathrm{S}-110$ shall be in process.

17. The Thrust Vector Con'rol Gimbal Iimits for Ground Test Trade Study (T. S. 1018) for Data Item Sa.054 shall be in process. 
1. Provide engineering, perform and report on radiation effects tests on materials using appropriate Data Items, T-102's (test specifications) and T-119's (test reporis) in accordance with the materials maturity specified in the Materials Property Test Test Priority and Maturity Report, dated May 15, 1970. The test reports $(T-119)$ shall be completed sixty $(60)$ days after the receipt of the acceptable test data.

2. Proviae technical liaison of irradiation test facilities engaged in NERVA or related testing of materials. Develop and refine radiation effects testing techniques and date reduction and evaluation methods. Evaluate facilities for radiation efrects testing.

3. Honitor and support the acquisition of pedigree data for materials to be tested.

4. Complete GTR-2OA reports on tests 37RO10 (Bearing Cage Naterials) and 37ROIl (Bearing Cages).

5. Complete GTR-2I reports. (Tests 37RO17, High Temperature Structural Materials and 37R018, Cryogenic Structural Materials.)

6. Complete preparations for irradiation of the following materials in GTR-2OC:

M-4 Ti 5AI 2.5Sn Forging (Fracture Toughness \& Tensile Tests 37NRO-029A \&: 028A)

(C)

1.1-1 Inconel 718 Forging (Fracture Toughness \& Tensile

M-5 A286 Bolts

M-3 Alum. 7039-T63 Forging Tests 37NRO-2OA \& 2IA) (Tensile Test 44NPO-IOI) (Fracture Toughness, Tensile, \& Weldments Tests 37NRO-044, -093)

M-12 Hastelloy-X Forging

M-2 347 S.S. Forging

M-6 AGC 101 (Coupons)

(Tensile Test 37NRO-054)

(Tensile Test 3TNRO-027)

(Test 3TNRO-206) 
1. Provide the effort to conduct the scope of work specified for Material Engineering as delineated in NERVA Management Plan, M-OOI, Volume III, Functional/Responsibility Matrix.

2. Perform work to meet the requirements defined in the NERVA Engine Naterials Plan, Data Item S-13I including the following:
a. Complete review of available designs, specifications and drawings for Engine Reference Design and signify compliance through established sign-off procedures.
b. Complete review of available designs, specifications and drawings for DRB and signify compliance through established sign-off procedures.

c. Submit monthly schedules status of work by means of a

d. Submit three supplements to the Materials Data Book, AGC-2275.

e. Submit Quarterly Materials Development Reports.

f. Publish Data Item S-13I and one revision.

3. Complete Contamination and Corrosion Control Plan, Data Item S-021.

4. Continue investigation of influence of high pressure gaseous hydrogen on the embritulement of structural alloys.

5. Conduct tests on the following Material Test Plans to establish statistically reliable data for mechanical and physical properties of materials required to support design of engine components in accordance with latest revision of the NERVA Materials Program Plan, RN-DR-0189. The degree of completion in CY 1970 of these tests is defined in the Material Property Test Priority and Maturity Report, dated May 15, 1970.

$\begin{array}{llll}\mathrm{M}-1 & \text { Inco } 718 & \mathrm{M}-9 & 6 \mathrm{Al}-4 \mathrm{~V}-\mathrm{Ti} \\ \mathrm{M}-2 & 3+7 \mathrm{SS} & \mathrm{M}-11 & \text { Vac-Friction } \\ \mathrm{M}-3 & 7039 \mathrm{AI} & \mathrm{M}-12 & \text { Hast X } \\ \mathrm{M}-4 & 110 \mathrm{AT} \mathrm{Ti} & \mathrm{M}-14 & \mathrm{PI}-\text { Polymer } \\ \mathrm{M}-5 & \text { A286 } & \mathrm{M}-19 & 440 \mathrm{CS} \\ \mathrm{M}-6 & \text { Fib Graphite } & \mathrm{M}-20 & 5086 \mathrm{AI} \\ \mathrm{M}-7 & 6061 \mathrm{Al} & \mathrm{M}-21 & 7075 \mathrm{Al} \\ \mathrm{M}-8 & 2024 & \mathrm{M}-23 & \text { Irrad GH2 }\end{array}$




\section{Suffix f - Development Engineering}

1. Conduct preliminary test planning and establish requirements for engine vibration tests.

2. Prepare and submit a plan for procuring system structural dynamic data utilizing the current dual pump test assembly in Test Cell "C". This olanning phase vill include the following activities:

a. Reduce existing accelerometer data from the Test Cell "C" turbopumo tests to obtain PSD plots of selected time slices.

b. Evaluate the existing data to select the most optimum planning for zuture structural dynamic testing with the same test assembly.

c. Evaluate the data recording system for acquisition of structural dynamic data at Test Cell "C".

d. Write a test jlan for system structural dynamic tests in order to yield maximum data applicable to I.ERVA engine design. The olan will include instrumentation loations and a recommendation for a recording system to permit rapid, accurate reduction of wide band data and correlation with narrow band pressure and TPA rpm data. 
13. Deleted

14. Coordinate and submit to SNPO-C changes to the EIS-1 F-4 as required.

15. Assist in the generation and review of the Test Cell " $\mathrm{C}$ " Facilities Requirement Document, F-4.

16. Prepare and submit for approval, a Form 9 outline for the EIS-I Activation Plan (F-5).

17. Prepare and submit the Preliminary EIS-1 Activation Plan (F-5). This plan shall detail logic only of all presently known modifications and major tests or construction efforts between now and the installation of E-I into EIS-I.

18. Prepare and submit for review and approval a Form 9 outline for the EIS-I Facility Design Criteria Document ( $F-7$ ).

19. Initiate preparation of ETS-I Facility Design Criteria (F-7).

20. Assist in the generation and review of the Test Cell "C" Facility Design Criteria Document (F-7).

21. Perform selected facility engineering studies in support of overall ETS-1 facility planning. Perform a conceptual analysis to derine the ETS-I thrust structure, which supports the NERVA engine utilizing the engine, fluid, electrical, thrust and vibration interface requirements to the extent engine/module data is available.

22. Conduct conceptual studies of facility checkout equipment. These studies shall be required at EIS-1 to the extent necessary to support development of the ETS-I F-4,F-5, and $\mathrm{F}-\mathrm{T}$ documents.

23. Perform NERVA NRDS Computer Requirements Studies as input to the NERVA Automatic Data Processing Plan.

24. Provide Engine Test Operations/Facilities representation to the AGC Change Board per the NERVA Configuration Management Plan (C-018). 


\section{PROTECT 224 - NERVA AITITUDE SI.ULATION SYSTE: - IRO}

\section{Suffix f - Development Engineering}

1. Complete, maintain or update and submit for approval, the following data items:
a. Duct-Basis for Design S-57
b. SGDS Procurement Specification C-2
c. Duct Preliminary Design Package F-8
d. Parametric Secondery Ejector Study
e. Program Plan, PERT Logic and Narrative Recorts, Test Plans, Prediction Reports and Test Reports

2. The duct design and SGDS Part I Specification (C-002) shalI satisfy the following requirements:

a. The reliability of the Exhaust Duct System (EDS) shall be such that no single failure or credible corbination of failures will prevent startup, operation or shutdown of an engine test. The design of the system shall inherently eliminate all potential failure including:

(1) Structural failures which would affect the conductance of hot hydrogen gases away from the test stend or result in unsatisfactory $\mathrm{H}_{2}$ concentrations in the $\Xi \mathrm{TC}$ or duct vault. No structural failure shall prevent satisfactory drainage of coolant water from the difiuser.

(2) Component malfunction or failure which would detrimentally affect secondary ejector pumping, hot gas stream cooling, or primary diffuser cooling.

b. The EDS shall meet the above requirements for an equivalent of at least 1000 full power NERVA Engine test firinss of 50 minutes each. It shall be a design goal to achieve 2000 full power cycles. The upper section of the diffuser may be designed with provision for replacement to achieve this objective.

c. The primary diffuser shall be evaluated to defire candidate configurations which will minimize the thermodjnemic loads. This evaluation snall include:

(1) Additional detailed analytical evaluation. 
(2) Configuration changes (i.e., spacing, convergency angle, etc.)

(3) Film cooling purge.

(4) Alternate diffuser coolant passage configuration.

d. The EDS shall be evaluated with inlet diameters from approximately 64 " to 72 " to determine a technically acceptable system attainable at minimum cost. Consideration should be given to the following:

(1) Allow plenum temperature to increase to the limit of stainless steel.

(2) Allow bulk gas temperature to approach $2500-3000^{\circ} \mathrm{R}$.

e. The following operational modes shall be achievable by the NASS, but not necessarily in the same day:

(1) Safety flow - provide low steam flow rate for two (2) hours - no altitude simulation.

(2) Partial power operation at engine chamber pressure from 200 - 350 psia - provide the necessary steam flow rate to maintain a full flowing engine nozzle for a duration of zbout 40 minutes and attaining 7 psia altitude simalation.

(3) Pulse cooldown - provide the steam flow rate to maintain a full flowing engine nozzle driven by run tank pressure of 20 psia and attaining $2-3$ psia altitude simulation. It is estimated that the engine flow rate will vary from 10 to $1 \mathrm{lbs} . / \mathrm{sec}$. at a gas temperature less than $2000^{\circ} \mathrm{R}$.

f. The following basic engine data shall be used in the NASS design:

(1) Chamber Temperature - $4385^{\circ} \mathrm{R}$; however, the EDS shall be capable of operation at $50000 \mathrm{R}$ at a reduced cyclic life.

(2) Thrust - 83,333 Ibs. 
(3) Flow Rate - 100 lbs./sec.

(4) Chamber Pressure - 500 psia

(5) Throat Area - 98.7 in. $^{2}$

(6) Area Ratio - 100:1 contour truncated at 60-in. I.D.

g. The following additional design requirements shall be satisfied:

(1) Primary diffuser

(a) Physically accommodate $\pm \frac{10}{2}$ gimbal with $E=24$

(b) Accommodate $0^{\circ}$ gimbal nozzle truncated at 60-in. I.D. maximum

(c) Utilize a split collar if desirable.

(d) Utilize zero misalignment tolerance (NOM)

(2) Secondary ejector and SGDS

(a) Provide capability for the future addition of a supplementary ejector to satisfy the pulse cooldown operational mode. The design of this ejector will be accoraplished at a later date.

(b) The SGDis shall be a stored energy system with a flow duration of about 40 minutes at a steam inlet temperature of $835^{\circ} \mathrm{R}$. nominal, and 3 day maximum system turn around ime.

3. The following Engineering Data shall be submitted in the Preliminary Design Package. The Preliminary Design shall be complete to the degree that a candidate system can be recommended with sufficient technical data to allow initiation of final detail design.

a. Analytical Studies including:

(1) Primary diffuser preliminary thermodynamic analysis.

(2) Primary diffuser preliminary aerodynamic analysis. 
(3) Preliminary structural and dynaric analysis.

(4) Final material selection evaluation.

(5) Nuclear Analysis.

(6) Reliability, safety and quality assurance analyses.

b. Scale Model Test Data including:

(1) Primary dizfuser tests.

(2) Water droplet tests.

(3) Secondary ejector steam optimization test.

(4) Final system test plans and predictions.

c. All conceptual and candidate configuration layout drawings.

d. Preliminary facility interface sheets (S-058).

(1) Prepare and submit for approval a Form 9 out Iine for the facility interface sheets (S-058).

e. Preliminary construction specifications.

(1) Rough draf: of fabrication specifications.

(2) Suggested special conditions.

f. Preliminary design drawings.

g. Initial cost estimates.

(1) Duct fabrication estimate.

(2) SGDS design and fabrication estimate.

4. Conduct a Preliminary Design Review (PDR) reviewing in detail the F-008 data submittal four (4) weeks after submittal.

a. AlI scale model testing described in Paragraph 3 above shall be complete prior to PDR. Results from the primary diffusers secondary ejector, and system test programs shall be presented.

b. Aerodynamic analysis, thermodynamic ana.lysis, and dynamic analysis shall be completed ard presented. 


\section{PROJECT 224 - Continued}

5. Initiate final detail design and preparation of the final design package (F-009) which will include:
a. All analytical studies
b. AIl scale model test data and reports
c. Final construction specifications
d. Final detail design drawings
e. Final cost estimates and schedule
f. Final facility interface sheets (S-058)

6. Provide Project Management, Design Engineering, Test Engineering and specialist support including, stress, thermodynamics, material, nuclear, reliability, safety and quality assurance to support the wor's scope defined in paragraphs I through 5 above. The primary emphasis of this effort will be:

a. Participation in and review of NASS design effort.

b. Performance of structural, thermodynamic, material, failure mode, and hazard analyses for the NASS design.

7. Verify adequacy of the primary ejector design to accept the engine nozzle.

a. Design and fabricate a scale model nozzle simulating the full scale 100:I area ratio nozzle contour except this nozzle shall be truncated at approximately $29: 1$ area ratio.

b. Conduct scale model tests to demonstrate compatibility with the primary ejector. If compatibility is not achieved, conduct that work discussed in Paragraph 8.

8. Develop a primary ejector geonetry compatible with the new 100:1 area ratio nozzle contour.

a. Determine a NASS primary ejector configuration compatible with the 100:1 area ratio truncated nozzle. This is to be accomplished by fabrication and testing with limited instrumentation alternate primary ejector configurations.

b. Design, fabricate, and instrument selected scale model NASS primary ejector configuration that is compatible with the $100: 1$ contoured nozzle. 
PROJECT 224 - Continued

c. Conduct scale model testing and analysis in order to evaluate the operational characteristics of the selected NASS primary ejector configuration.

9. Determine performance of a primary ejector with a countoured inlet.

$(\mathbb{N})$

a. Conduct analytical effort in order to determine optimum primary ejector inlet contour.

b. Design, fabricate, and instrument the contoured inlet primary ejector configuration.

c. Conduct scale model testing and analysis on the contoured inlet primary injector.

10. Determine performance of a primary ejector with a revised nozzle skirt extension contour.

a. Conduct analytical effort to determine optimum skirt contour for best primary ejector performance.

b. Design, fabricate, and instrument skirt extension.

c. Conduct scale model testing and analysis on the revised skirt extension. 
Suffix f - Development Engineering

1. Contribute to trade studies and related program logic and analyses to ensure that the effects of potential modes of component and system failure are minimized and optimum requirements established to provide emergency modes of engine operation. Result; will be documented by AGC internal memoranda to support conceptual Engine PDR.

2. Conduct overall system failure efiects and malfunction analyses using applicable failure mode analyses to further aid in the derivation of flight safety requirements on components, subsystems and the engine system and to establish engine emergency modes and procedures. Conduct these activities in concert with the subcontractor, designers, systems analysis, and reliability activities. Incorporate results in draft version of Data Item S-103.

3. Use fault tree analysis to identify and investigate the effects of potential single or combinatory failure modes that could result in selected undesired events peculiar to flight safety. Incorporate results in draft version of Data Item S-103.

4. Ensure as appropriately scheduled that component, subsystem and system requirements peculiar to flight safety to support DRB and Engine PDR are presented in appropriate specifications and design sheets and that the results of allied analyses are presented in appropriate data items. Provide assistance as needed in the systems engineering activities to establish safety requirements. Input will be documented by AGC internal memoranda.

5. Provide contingency worksheets keyed to failure modes to consolidate the flight safety requirements activity. Use this (c) vehicle to identify critical single point failures. Incorporate results in draft version of Data Item S-103.

6. Conduct studies to determine the desirability of using an inflight poison system. Provide input to WANL Trade Study 719 via AGC letter.

7. Establish preliminary requirements for the flight terminationdestruct system. Input will be via AGC internal memoranda.

8. Conduct analyses to determine the transport characteristics of fission and corrosion products in space. Document results by AGC internal memorandum. 


\section{PROJECT 251 - Continued}

9. Participate as scheduled in the activities of the Nuclear Rocket flight safety panels. Coordinate the flight safety and related efforts of the subcontractor and other participating agencies.

10. Prepare draft version of Data Item S-103. The fault tree analysis and contingency analysis contained in this draft will reflect, as a minimum, the documented status of engine design and analysis performed by projects other than Projects 251 and VANL 851 that exists on August 15, 1970. The CfN malfunction analysis incorporated at this time will be limited to information available from control study analysis. Fault Tree analys is will be limited to consideration of Branch B of the Top Level sault tree.

11. Revise the flight operational safety aspects of the Safety Engineering Plan, Data Item S-019, and in conjunction with the Subcontractor and Project 24I, reissue S-019.

12. Complete safety analysis procedures for the implementation of the overall engine system flight safety effort. The procedures to be published are:
a. Fault Tree Analysis
b. Flight Safety Contingency Analysis 
PROJECT 262 - QUALITY ASSURANCE - NRDS

Suffix b - Technology Engineering

1. Quality Assurance - Technology Program

a. As a part of INTO provide support for disassembly, postoperative and storage activities associated with XE Prime and $\mathrm{XE}$ Backup assemblies.

Suffix $f$ - Development Engineering

As a part of NTO perform the following:

1. Quality Assurance - NERVA Program

a. Provide necessary inspection and support for the Dual Mode Pump Program and complete the NTO assembly and checkout log books.

b. Maintain the audit log report in verification of the EIS-1 Baseline drawings and specifications.

c. Provide support for the modification, repaics and maintenance activities at ETS-I and E-MAD, including equipment calibration and certification.

d. Complete the NTO Quality Assurance Plan and provide input to the NTO Management Program Plan.

e. Provide support for the NRDS flatcar brake and coupler modifications performed at E-MAD.

f. Establish a computer program and analyze all documented XE testing discrepancies and anomalies to define problem areas and provide data to design activities for subsequent upgrading of facilities.

g. Establish a computerized failure reporting and corrective action system.

h. Conduct quality audits on modification and preventive maintenance programs, subcontractor efforts and other NRDS activities.

i. Participate in a Quality Assurance review of Preliminary Engineering Report (PER) studies for NRDS facilities as required by FEO. 


\section{PROJECT 262 - Continued}

Suffix y - Pewee and Nuclear Furnace

As a part of NTO perform the following:

1. Quality Assurance - LASL Programs

a. Provide support for the Pewee 2 test car and facility flow car assembly and maintain the Pewee 2 Quality Assurance inspection log.

b. Provide support for the Nuclear Furnace 1 test car and shield buildup.

c. Implement the following programs at Test Cell "C" after $7 / 1 / 70$ :

(1) Failure Analysis and Discrepancy Reporting System

(2) Quality Assurance surveillance of test facility modifications.

(3) Quality Assurance surveillance of facility system checkouts. 


\section{Suffix $f$ - Development Engineering}

1. Develop and publish reliability methods and procedures for proper implementation of the overall engine system reliability effort. The detailed procedures, salient features of the Reliability Plan, encompass all facets of the development effort and shall be estabiished in order to accommodate trade study and reference engine analysis, engine system and component analysis and design, and test activities. Each procedure shall be developed to the extent needed for use within the program as dictated by major program milestones. The procedures will be revised, improved and updated as necessary to accommodate the technical progress within the program. Establish and maintain an index of NERVA Reliability Procedures.

a. Provide for early submittal an abstract of each procedure defining its content and scope.

b. The formal index shall be established to provide continuously the status of all reliability procedures contemplated for use in the NERVA Program, Provide monthly submittal of status of the procedures.

c. The procedures to be established are as follows:

(1) For trade study support, early selected testing and reference engine analysis.

(a) System Failure Mode Effect and Criticality Analysis .

(b) Component Failure Mode Analysis.

(c) Reliability apportionment.

(d) Trade Study Reliability Analysis.

(e) Reliability Review of Test Plans.

(2) For component evaluations, engine and component preliminary design review.
(a) Structural Reliability Techniques.
(b) Mechanical Reliability Techniques. 
(c) Electronic Component Reliability Analysis

(d) System and Component Reliability Mathematical Models

(e) Statistical Distributions, their applications and tables

(f) Deleted

(g) Deleted

(h) Reliability model for multiple cycle redundant system

(i) Failure Rate Derivation

(j) Part size and configuration effect

(k) Reliability Prediction of Rotating Machinery Vibration Mode

(1) Reliability calculation for the cases of combined stress and fatigue loading.

(m) Applicable strength theory for selected failure modes.

(n) Success-Rate assessment method

(3) For the end of the Contract Year

(a) Subcontractor and Vendor Reliability Plans

(b) Component and Procurement Specification Reliability Requirements

(c) Vendor Rating and Control System and Reliability Audit

(d) Error in assumption of normality. 
Rev. $7-7-70$

PROJECI 263 - Continued

(e) Apolication of Redundancy to Instrumentation and Controls Components

(f) The use of Random Number Generators

(g) Parts and Material Data Selection and Control Sistem

(h) Single Failure Point Reporting, Analysis, Correction and Closeout

(i) Failure Resolution Board

(j) Deleted

(k) Glossary of Reliability Terms

(1) Reliability Data Collection and Reporting System

(m) Sampling procedures for fatigue testing of sjecimen parts

(n) Deleted

(o) Statistical analysis of materiel testing

d. The milestones will be met by internal issuance of the procedures, as indicated by milestone dates, by reliability; and by the issuance of a monthly report of the index and status of the procedures.

2. Provide consultation to system engineering efforts to assure perceptive reliability evaluations of alternate concepts in support of trade studies requiring reliability evaluation. Participate in trade study effort, directly, by providing math modeling, probabilistic analysis, Failure Mode lifects and Criticality analysis and reliability ranking methods where necessary. This task will be satisfied with internal memorandum summarizing reliability review of Category B system trade study reports.

3. Provide consultation on each component design effort to assure perceptive Failure Mode Analysis and probabilistic analys is in design to accommodate engine and component PDR. Participate in component trade studies and in reviews of component Failure Mode Analyses to assure completeness of design effort and 
efforts of supporting discipline. This task milestone will be satisfied with internal memorandum summarizing Reliability Review of component S-054, R-202 and other appropriate analys is reports containing Failure Mode Analysis supporting concept selection.

4. Prepare reliability allocations for the reference engine components in support of preparation of specifications. Revise allocations as necessary for Engine PDR. Perform reliability modeling for the engine system as a function of the reliability reference mission time and cycles including the transient and steady state operations. Perform reliability predictions for the engine systems for engine PDR. This task will be satisfied by the following:

a. By the preparation and updating of the reliability math model and allocations data to support DRB.

b. By incorporation of the updated reliability math model, the updated allocation and the engine system reliability prediction, into the draft of Data Item $\mathrm{R}-202$.

5. Prepare system level Failure Mode Effects and Criticality Analysis (FIECA) for engine PDR. In conjunction with safety analysis, perform Single Failure Point (SFP) identification and analysis based upon the Failure Mode Effects and Criticality Analysis. Provide assistance in establishing optimum selected engine emergency operating modes, emergency procedures and requirements. This work will be progressively accomplished and coordinated with the safety analyses as required for engine PDR. Milestone will be met by incorporation of FIECA and SFP analysis into the draft of Data Item $R-202$.

6. Participate in development and review of all materials, components, radiation effects, and system test plans to assure proper statistical analysis of reliability data. Milestones will be met by the reliability review and approval of specific test plans, as defined by the NERVA Management Plan (Data Item M-001).

7. Provide preliminary documentation, maintain and update computer programs for reliability math model and data analysis. Utilize computer and computer programming with respect to singular reliability analyses. Search, identify and collect existing programs associated with reliability. Coordinate and exchange computer programs as necessary with WANL. The milestone shall be met by making internal documentation available for Government reviews. 
PROJECT 263 - Continued

8. Establish and participate in the Failure Resolution Board. Participate with Engineering and Quality Assurance in the preparation of Failure Analysis and Corrective Action System Procedures. Milestones will be met by internal issuance of FRB procedures by Reliability.

9. Provide data and assistance to support the preparation of other data items pertinent to the reliability effort. Provide consultation in establishing engine and reactor test facility reliability requirements. Coordinate reliability efforts with the maintainability effort. Provide systems Failure Mode Effects and Criticality Analysis and failure probability estimates input to the maintainability effort. Participate in review of maintainability output. Coordinate reliability program and prepare and participate in status review and major presentations with SNPO, WANL, stage and associated contractors. Participate in the resolution of common reliability problems.

10. Conduct reliability training, indoctrination and awareness programs with design, analytical, system and test engineers. Upgrade reliability personnel through eduction, training and motivation in current advanced reliability techniques and reliability management principles using outside consultants, university short courses, symposium and internal training programs. Maintain an awareness and visibility of other exemplary reliability programs throughout the country.

11. Prepare a draft of Data Item R-202 for the engine and nuclear subsystem. This draft version will contain updated mathematical models, logic diagrams, reliability allocations and predictions, engine system FIECA's single failure point listings, and a preliminary listing of trend characteristics. The malfunction analysis which supports the FMECA will be limited to information available from control study analysis performed using CAM. The maturity of these items will reflect, as a minimum, the documented status of engine design and analysis performed by projects other than Projects 263 and 863 that exists on 15 August 1970.

12. In participation with SNPO-C, finalize the Data Item R-106 Form 9 within 30 days after approval of the $\mathrm{T}-102$ Form 9.

13. Within sixty (60) days after receipt of Government comments on the informal draft of Data Item R-101, revise, update and publish the Reliability Plan, R-101. Milestones will be met by formal submittal of $\mathrm{R}-101$.

14. Provide review and technical coordination of reliability effort at WANL. 


\section{PROJECT 263 - Continued}

15. Establish and publish the detailed procedures and forms required to implement the trend data activity. These procedures shall be prepared initially during the component concept selection activities and embrace component iailure mode analysis and error analysis which identify the critical parameters and statistical limits comprising the trend analysis program. These procedures will include practices to be followed during design, prior to testing, during test and subsequent to testing of parts, components, subsystems and the engine system. Prepare for early submittal of an index of the procedures and an abstract of each procedure to identify the content and general scope.

Salient trend data parameters shall be published initially to support each Design PDR and Data Item R-2OE under trend data characteristics, variations and measurements. The milestone will be met by:

a. the issuance of the index and abstracts of the procedures.

b. procedures.

c. documenting preliminary trend data characteristics into

16. Provide consultation to Systems Analysis in the determination of engine operating requirements and the development of the mathematical and statistical techniques for propagation of error analysis to insure the adequacy of the error analysis in determining the variation in engine state points. 
j. Effective July 1, 1970, provide the following:

(1) Develop a program of priorities and urgencies for systematic verification of Test Cell "C" Product Configuration Baseline.

(2) Implement the program of verification of the Test Cell "C" Product Configuration Baseline, including:
(a) Specieications
(b) Drawings
(c) Supporting Calculations 
Suffix $f$ - Development Engineering

1. Conduct design engineering including nuclear, thermal, and stress analyses to produce a nozzle extension design suitable for testing on the Pewee, in order to obtain regression rates and data on nozzle extension flange structural integrity. Work to be conducted prior to 15 August 1970.

\section{Suffix i - Development Fabrication}

1. Procure material and fabricate a nozzle extension for testing on the Pewee reactor nozzle. Part to be completed and instrumented by 15 september 1970 and shipped to IASL for final machine and assembly. Bolts and seal to be provided by Aerojet Nuclear Systems Company.

2. Fabricate test specimen and obtain material properties to support analyses required.

(New project - does not replace Page 145.) 
PROJECT 391 - Continued

11. Design and fabricate metallic fluidic driver amplifiers. Conduct necessary support services of heat transfer stress and fabrication methods.

12. Perform necessary fluid-mechanical anlysis for evaluation of fluidic vortex valve and amplifier diffusers.

13. Perform preliminary design studies on flow diversion valves. Fabricate and test a selected subscale design.

14. Conduct geometry and flow parameter optimization of plastic model temperature sensors at ambient conditions.

15. Design and fabricate an intermediate temperature range sensor. Support services will include heat transfer, stress and fabrication method selection.

16. Conduct preliminary design studies of a flight engine breadboard tmperature sensor. Fabricate a plastic model of the selected configuration.

17. Conduct exploratory tests of Pluidic driven metallic amplifiers at cryogenic conditions.

18. Complete testing of an intermediate range $\left(\sim 2500^{\circ} \mathrm{R}\right)$ temperature sensor. 


\section{PROJECT 396 - Continued}

a. Measure yield stress of gel by weighted sphere method and confirm values of yield stress by the rising disc method.

b. Determine viscosity of the gel using the flow measurement method.

c. Demonstrate storability of gel for a minimum period of eight (8) hours.

6. Reports - The contractor shall prepare and distribute a monthly letter report. The monthly reports shall be distributed by the tenth (loth) calendar day of the following month. The first monthly letter report shall include a tabular presentation of the experinental runs and variables to be studied. This test matrix shall be updated monthly.

7. Prepare and distribute a final report.

Phase II, April 1, 1970 through September 30, 1970

1. Prepare on a laboratory scale suspensions of hydrocarbons in liquid hydrogen. The procedure used for preparation of the small particles of hydrocarbons is the injection of a gaseous stream of hydrocarbons diluted with hydrogen into liquid hydrogen. The subsequent condensation process produces the very small hydrocarbon particles.

The work required is divided into four tasks: (I) Optimize Preparation of Ultrafine Hydrocarbon Particles, (2) Gelation of Liquid and SIush Hydrogen, (3) Fuel Storability Demonstration, and (4) Fuel. Characterization, hereafter described.

2. Task 1. Optimize Preparation of Ultrafine Hydrocarbon Particles

To increase the concentration of ultrafine hydrocarbon particles, the preparative procedure will include a flowing liquid hydrogen system in order to minimize formation of the larger particles. The optimum dilution ratio of hydrocarbon/hydrogen in the initial gas stream for the formation of small particles will be established. The product solution will be sampled periodically to determine the concentration of the hydrocarbons in the liquid hydrogen. The prime hydrocarbon candidate is cyclopropane.

3. Task II. Gelation of Liquid and SIush Hydrogen

The optimum conditions for producing hydrocarbon particles to serve as gelants for liquid hydrogen will be determined. The gels will be analyzed to determine the concentration of the 
PROJECT 396 - Continued

gelant. The best hydrocarbon gelant will be used to prepare a gelled slush hydrogen product. Analysis of the product will be used to establish the quantity of gelant required to produce a stable hydrogen slush. The prime hydrocarbon candidate is ethane.

4. Task III. Fuel Storability Demonstration

The colloidal suspension obtained in Task I will be stored for periods up to five days with periodic sampling to determine the hydrocarbon particle concentration. The gelled hydrogen obtained in Task II will be stored for periods up to five days to demonstrate the storability characteristics of the product.

5. Task IV. Fuel Characterization

The gelled hydrogen product will be characterized with respect to the yield stress values required for stability of the gel. In addition, the viscosity of the optimum product will be determined at several shear rates. The data obtained from this task will provide the preliminary engineering design data for flow systems for the gelled product.

6. Reports

The contractor shall prepare and distribute a monthly letter report. The monthly reports shall be distributed by the tenth (10th) calendar day of the following month. The first monthly letter report shall include a tabular prasentation of the experimental runs and variables to be studiel. This test matrix shall be updated monthly.

7. Upon completion of Phase II effort which shall occur on or before September 30, 1970, prepare and distribute a final report. 
Suffix a - Support

1. As host to the March 2-5, 1971 National Symposium on ManMade and Natural Radiation in Space perform the following effort during Contract Year 1970:

a. Prepare preliminary announcement including notification of date, location and content of symposium and the initial call for papers. Publish appropriate announcement data in journals and periodicals.

b. Prepare a plan showing the initial program format and initiate action leading to selection of guest speakers.

c. Prepare material for review in a meeting with the program committee for use in preparation of a preliminary program agenda.

d. In this effort conduct as appropriate general publicity, coordination, correspondence, arrangements for facilities.

(New project - does not replace Page 156 contractual work statement) 
PROJECT 6I3 - REACTOR SYSTEMS ANALYSIS

Suffix $f$ - Development Engineering

1. Maintain and upgrade, with assistance from WANL, a Common Analog Model for the R-l Reactor and Test Cell "C". Request special runs be made on the implemented Common Analog Model at .ANL as necessary for AGC-supplied components. Update the AGC-supplied components based on design anc test data. Evaluate the model periodically for assurance that tre implementation of the model on the computer is correct. tions.

2. Provide updated input for nuclear subsystem DRB specifica-

3. Update the $\mathbb{N E} T A P$ program representations of the nuclear subsystem. This will include the incorporation of a detailed model of the structural support system, upgrading the neutronics, and other improvements in the program required to better represent the nuclear subsystem.

4. Evaluate the hydrogen properties used in the systems analysis and improve the properties decks to give agreement with the National Bureau of Standards generating codes. This will be documented by presentations to the Customer and by internal memoranda.

5. Evaluate computer requirements in support of $R$ testing and at WANL as part of the ADP long range plan. The information will be documented by letters and minutes of meetings and will input into a report to be issued by SNPO-W. required.

6. Implement recommendations of long range ADP plan as 
PROJECT 621 - PPESSURE VESSEL AND CLDSURE SUBSYSTEM

Suffix f - Development Engineering

1. Update Sections 1,2,3,6, and preliminary 10 of Data Item C-002 CEI/CC Part I Specification for the Pressure Vessel and Closure subsystem to support DRB.

2. Complete Section 4 of the C-OO2 CEI/CC Part I specification for the Pressure Vessel and Closure subsystem to support Engine PDR.

3. Complete preliminary design concept selection to support Conceptual Engine PDR.

4. Complete nuclear analysis to support the design concept.

5. Complete steady state thermal and fluid flow analysis in support of $\mathrm{S}-03 \mathrm{I}$.

6. Complete preliminary stress analysis to support concept selection.

7. Complete steady state intermediate stress analysis in support of $\mathrm{S}-036$.

8. Complete basic weights analysis (Data Item S-047) for selected concepts.

9. Complete preliminary draft of the Category "C" portion of Pressure Vessel Assembly Designstudy report (T.S. 601) for Data Item S-054.

10. Complete input to update of Data Item S-O01.

11. Complete Pressure Vessel Assembly FMA and estimate of the pressure vessel reliability goals can be met (Modes and Mechanisms only).

12. Make pressure vessel materials selection and transmit decisions for inclusion into Data Item $\mathrm{S}-110$.

13. Complete pressure vessel assembly launch criteria to support Data Item S-038.

14. a. Complete a preliminary layout of the selected design

b. Provide E-105 Engineering Backup. 
Rev. $7-7-70$

\section{PROJEIT 621 - Continued}

15. Initiate and maintain in process the following effort:

a. Pressure vessel heating rates for inclusion into D ta Item S-100 shall be in process.

b. The detailed design layout of the selected concept (Data Item E-105) shall be in process.

c. Transient thermal analysis for startup and shutdown conditions shall be in process.

d. Transient stress analysis for startup and shutdown conditions shall be in process.

e. ROM dynamic (vibration) analysis shall be in process.

f. Efforts to support Data Items S-031, S-038 and S-039 shall be in process.

g. Stress and favigue analysis to support Data Item S-036 shall be in process.

h. Establishment of reliability goals (exclusive of numerical analysis) as input to Data Item $\mathrm{R}-202$ shall be in process.

i. Coolant channel design characteristics input for Data Item S-OOl shall be in process. 
PRO JECT 641 - STRUCTURAL SUPPORT COOLANT VALVE

Suffix f - Development Engineering

1. a. To support DRB, complete Data Item C-002 CFI/CC Part

I, Sections $1,2,3,6$, and preliminary 10 specification which includes the requirements for the SSCV.

b. Complete Data Item C-002 CEI/CC Part I, Secions 1, 2,3 , and 6 specification format draft for the SSCV.

2. Complete a prelimirary Section 4 of the C-002 Specification.

3. Complete the selection of the primary SSCV valve candidates for conceptual design study to support Conceptual Engine PDR. Report results in an internal ACC memorandum.

4. Complete simple Iailure mode analyses on selected concepts as input to Data Item R-202 Reliability Allocations, Assessments and Analyses (Modes and Mechanisms only).

5. Complete a preliminary layout (Data Item E-105 Engineering Data for Design Evaluation) of the final valve concept.

6. Complete an engineering, draft (excluding transient effects) for T.S. No. 103-S-054 requirements/Trade Study Report for the SSCV.

7. Nuclear analysis input for Data Item S-100 Radiation and Shielding Analysis Report. Complete the preliminary thermal analysis and initiate preparation of the thermal model (S-03I Thermal and Fluid Analysis Report).

8. Coordinate $S S C V$ requirements with WAIT and define the SSCV valve-actuator interface.

9. Preliminary stress calculations of the SSCV shall be in process.

10. Conduct necessary design analyses to support the following trade studies.

a. 021 Engine System Rated Performance

b. 022 Post Shutdown Operations

c. 026 Startup and Shutdown Ramps and Throttleability and Chilldown.

d. 032 Actuator Drive Power 
Rev. $7-7-70$

\section{PROJECT 641 - Continued}

e. $\quad 101$ Propellant Feed Subsystem

f. 103 Engine Valve

g. $\quad 1003$ Maintainability Inflight and Ground

h. 1004 Engine Acceptance Test

11. Preparation of the required sections of the folloring data itemis to support specification update for Ergine PDR shall be in process.
a. S-001 Systems fnalysis Summary Report (Steady State)
b. S-038 Dynamic AneIj sis Summary Report
c. S-039 Loads Report 
PRO.JECT 643 - STRUCTURAL SUPPORT ELCCK VALVE AND ACTUATTR

\section{Suffix f - Development Engineering}

1. To support Conceptual Engine PDR, complete the selection of the primary SSBV valve and actuator candidates for conceptual design study. Report results in an internal AGC memorandum.

2. a. To support DRB, complete Data Item C-002 CEI/CC Part 1 , Sections 1, 2, 3, 6, and preliminary 10 Specification which includes the requirements for the SSBV and actuator.

b. Complete Data Item C-002 CEI/CC Part I, Sections 1, 2,3 , and 6 specification format draft for the SSBV.

3. Complete preliminary Section 4

4. Complete the preliminary concept selection of the valve for the reference engine.

5. Complete simple failure mode analyses on selected concepts as input to Data Item R-202 Reliability Allocation, Assessments and Analyses (Modes and Mechanisms only).

6. Complete a preliminary layout (Data Item E-105 Engineering Data for Design Evaluation) of the final valve and actuator concept.

7. Complete an engineering draft (excluding transient effects) of Trade Study No. 103 for Data Item S-054 Requirements/ Trade Study Report for the SSBV.

8. The nuclear analysis for Data Item S-100 Radiation and Shieläing Analyses Report shall be in process. Complete steady state thermal analysis of the critical SSBV parts (S-03I Thermal and Fluid Analysis Report).

9. Conduct necessary design analyses to support the following trade studies:
a. 021 Engine System Rated Performance
b. 022 Post Shutdown Operations
c. 026 Startup and Shutdown Ramps and Throttleability and Chilldown.
d. 032 Actuator Drive Power
e. $\quad 101$ Propellant Feed Subsystem
f. 103 Engine Valve
g. 419 Engine Electrical Power Supply Requirements 
PROJECT 643 - Continued

h. 420 Instrumentation and Control Slibsystem

i. 422 Wiring Harness

j. 1003 Maintainability Inflight and Ground

k. 1004 Engine Acceptance Test

10. Preparation of the required sections of the following data items to support the specification update for the

Engine PDR shall be in process:

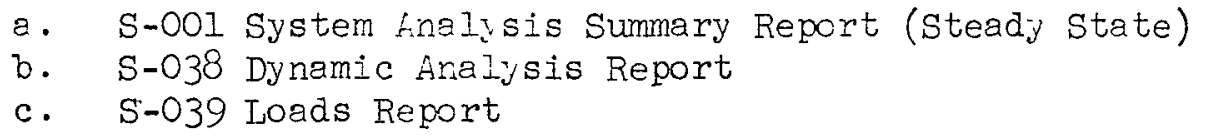

11. Write a computer program and conduct acalyses of preliminary transient response $t$ imes, acceleration values, motor power and transient current requirements based on conceptual valve and actuator desigrs. Report results in internal AGC memoranda and provide as input data to S-054.

12. Preliminary stress calculations on conceptually selected actuator gear and learing types based on valve illewias, mass, predicted accelaration values and preliminary thermal valves shall be in process. 
PROJECT 672 - TEST CELI "C" OPERATIOHS

Suffix $f$ - Development Engineering

As a part of Joint Test Organization (JTO) perform the following for the period October 1, 1969 through June 30, 1970:

1. Assist IASI in the operation of the Test CelI "C" facilities during the Nuclear rurnace, Pewee and Turbopump experiments. In addition, perform the following:

a. Maintain cognizance of the test facility modifications and operating characteristics and maintain a change documentation system.

b. Naintain cognizance of the test programs as pertains to Test Objectives, Operations and Test Results.

c. Obtain operator training and experience in key control room operating positions.

d. Obtain training and experience in JTO controls group, test planning, cell operations and data group.

e. Assist IASL in developing and documenting 7094 computer software to support the following Test Cell "C" data reduction capability.

(1) Engineering unit conversion.

(2) Support for Cal Comp plotter to make time history, multiple plots and cross plots.

(3) 7094 engineering calculations.

(4) Report generation for DDP 116 programs.

f. Assist LASL in developing and documenting DDP 116 computer programs to supjort Test Cell "C" operations. This support will include application programs in support of Test Cell "C" testing and systems software development. 


\section{PROTECT 672 - Continued}

b. Perform Pewee 2 and Nuclear Furnace facility checkout test operations and local tests in support of Pewee 2 .

c. Prepare for Test Cell "C"/Pewee 2 readiness review.

d. Continue preparation of test planning documentation such as experimental plans, reactor test plans, status board memos, set-up cnecklists, dry run checklists and control room checklists for Pewee 2 facility checkout test, Pewee 2 tests, Nuclear Furnace facility checkout tests and NF-I tests.

e. Review test, failure mode and malfunction analysis provided by LASL. If necessary, perform, or have performed, additional analjsis to meet NTO requirements.

f. Review LASL safety documentation to assure NTO safety requirements have been satisfied. If necessary, perform, or have performed, additional safety analysis to meet NTO requirements

g. Continue support to NERVA Test program planning.

2. Instrumentation and Control and Data

a. Perform test data reduction and analysis for Nuclear Furnace facility checkout, jet pump test and Pewee 2 facility checkout tests and issue test reports.

b. Continue Test CeII "C" facility, control and instrumentation modifications and checkout in support of Pewee 2 and Nuclear Furnace 1 test.

c. Continue development and documentation of 7094 computer software to support iest Cell "C" data reductions.

d. Continue development and documentation of DDP-116 computer program for Test Cell "C" operations in support of Pewee 2 and Nuclear Furnace 1 test.

\section{Test Cell "C"}

a. Continue Test Cell "C" facility daily operations in support of assigned programs.

b. Conduct flow tests and other component testing as required by NRDS operations. 
c. Initiate the imolementation of NTO Configuration lianagement for Test Cell "C" facility.

d. Perform the necessary system analysis for facility modification design.

e. Continue develcpment of Radiation Safety monitoring system for Nuclear Furnace Scrubber System.

f. Provide technical direction of Rocketdyne support for the purnp effort.

g. Provide coordination and input to interface agreement for nonnuclear component testing at Test Cell "C".

h. Provide input to the Pewee II and ITuclear Furnace I test planning by reviewing experimental plans, summary test plans, and control room operating procedures.

i. Review the ground test safety documentation (SAR, SER, and OID) for Pewee II and Nuclear Furnace I.

j. Assist NTO in the Test Cell "C" operator training program.

k. Provide test engineering review of detailed proposed changes to the Test Cell "C" facility to assure compatibility with the overall Test Cell "C" test program. 


\section{PROJECT 673 - MAD BUITDTTIG ODERATIONS - INUCTEAR SUBSYSTEIS}

Siffix y - Pevee and Niclear Furnace

As a part of NTO, perform the following support:

1. Continue a facility and facility-related equipment maintenance program in support of Nuclear Subsystem Operations.

2. Maintain $L-1, L-2, I-3$ MCC and spacer in operating condition to support IASL test program.

3. Effective July 1, 1970, assume responsibility for management of R-MAD Facility and associated equiprent and perform the following:

a. Maintain the R-IAD facility in a caretaker mode.

b. Continue support to maintain and perform minor modifications in preparation for and operational checkout of Fuel Element Processing (FEPS) in support of Pevee 2.

c. Install and checkout INSIPID Camera System.

d. Define requirements for procedural documentation necessary to assume R-MAD management responsibility including safety, security and maintenance of $\mathrm{GFE}$ and $\mathrm{GSE}$. Begin preparation of documentation.

e. Assume responsibility for LASL rolling stock, including test cars, flatcars and locomotives. Integrate hardware and existing documentation into NTO systems.

f. Assume responsioility for accountability of R-MAD severable equipment and GSE, based on current established inventories and locations. Document per NIO procedures. 
PROJECT 691 - TEST CELL "C" OPERATIONS

Suffix y - Pewee and Nuclear Furnace

As a part of NTO assume management of the Test Cell "C" facilities effective July 1, 1970 and perform the following:

1. Test Operations

a. Define and implement an operator training program to support Pewee 2 and Nuclear Furnace 1.

b. Perform Pewee 2 and Nuclear Furnace facility checkout test operations and local tests in support of Pewee 2 .

c. Prepare for Test Cell "C"/Pewee 2 readiness review.

d. Continue preparation of test planning documentation such as experimental plans, reactor test plans, status board memos, set-up checklists, dry run checklists and control room checklists for Pewee 2 facility checkout test, Pewee 2 tests, Nuclear Furnace facility checkout tests and $\mathrm{NF}-1$ tests.

e. Review test, failure mode and malfunction analysis provided by LASL. If necessary, perform, or have performed, additional analysis to meet NTO requirements.

f. Review LASL safety documentation to assure INO safety requirements have been satisfied. If necessary, perform, or have performel, additional safety analysis to meet NTO requirements.

g. Continue support to NFRVA Test program planning.

2. Instrumentation and Control and Data

a. Perform test data reduction and analysis for Ivclear Furnace facility checkout, jet pump test and Pewee 2 facility checkout tests and issue test reports.

b. Continue Test CelI "C" facility, control and instrumentation modifications and checkout in support of Pewee 2 and Nuclear Furnace 1 test.

c. Continue development and documentation of 7094 computer software to support Test Cell "C" data reductions.

d. Continue development and documentation of DDP-116 computer program for Test Cell "C" operations in support of Pewee 2 and Nuclear Furnace 1 test. 


\section{PROETCT 691 - Continued}

3. Test Cell "C"

a. Continue Test Cell "C" facility daily operations in support of assigned vrograms.

b. Conduct flow tests and other component testing as required by NRDS operations.

c. Initiate the implementation of INTO Configuration Management for Test Cell "C" facility.

d. Perform the necessary system analysis for facility modification design.

e. Continue development of Radiation Safety monitoring system for Nuclear Furnace Scrubber System.

f. Provide technical direction of Rocketdyne support for the pump effort.

g. Provide coordination and input to interface agreement for nonnuclear component testing at Test Cell " $\mathrm{C}$ ".

h. Provide input to the Pewee II and Nuclear Furnace I test planning by revieving experimental plans, summary test plans, and control room operating procedures.

i. Review the ground test safety documentation (SAR, SER, and OLD) for Pewee II and Nuclear Furrace I.

j. Assist NTO in the Test Cell "C" operator training program.

k. Provide test engineering review of detailed proposed changes to the Test Cell "C" facility to assure compatibility with the overall Test Cell "C" test program.

1. Convert IASL requirements to NTO work packages for facility mechanical modifications.

m. Support Test Cell "C" in liaison function with LASL personnel in Los Alamos. 


\section{PROJECT 692 - $\because A D$ BUIIDING OPERATIOI:S}

Suffix $y$ - Deriee and Nuclear Furnace

As a part of NTO, perform the following support:

1. Provide support for IASI programs.*

a. Complete Pewee 2 flow car. Complete Pevee 2 test car.

b. Complete buildup of NF-I test car.

c. Complete assembly of $M T H-1$ shield.

2. Effective July I, 1970, assume responsibility for management of R-liAD Facility and associated equipment and perform the following:

a. Iritiate Pewee 2 test article test car mate-up operations.

b. Provide input as required to the NTO test artical and facility support group regarding documentation prepared for assembly operations of LASI test articles and related facility TSE.

3. Effective July 1, 1970, support E-MAD effort by jerforming engineering services required to:

a. Convert LASI requirements to NTO Procedures for test article maintenance, assembly and disassembly.

b. Support E-MAD in liaison functions with IASL personnel in Los Alamos.

c. Supply the engineering design, drafting and analysis effort for TSE and RTS equipment.

*Completion dependent upon LASL schedules. 
Rev. $7-7-70$

As a part of NTO, provide the following:

1. ETS Rolling Stock Modifications

a. Complete the inctallation of necessary hardware to accomplish modifications of brakes and couplers on F-4, F-9 and L-1.

b. Installation on a level of effort to the extent of manpower available, of necessary hardvare to accomplish modifications of brakes and couplers on F-3, F-5, F-7 and the LRI Dump Car.

2. Equipment and Facility Maintenance

a. Complete brake and coupler modifications to LASL test cars.*

(1) Pewee $2(\mathrm{~T}-4)$

(2) $\mathrm{NF}-1(\mathrm{~T}-3)$

*Completion dependent upon IASL schedule. 